\title{
Energy Efficiency of Hollow Fibre Membrane Module in the Forward Osmosis Seawater Desalination Process
}

\author{
${ }^{* 1}$ Ali Altaee, ${ }^{2}$ Ali Braytee and ${ }^{3}$ Graeme J. Millar \\ ${ }^{1}$ Centre for Technologies for Water and Wastewater, School of Civil and \\ Environmental Engineering, University of Technology Sydney, 15 Broadway, NSW \\ 2007, Australia. Email: ali.altaee@uts.edu.au tel:+61(2)95149668 \\ ${ }^{2}$ School of Biomedical Engineering, University of Technology Sydney, 15 Broadway, \\ NSW 2007, Australia. \\ ${ }^{3}$ Institute for Future Environments, Science and Engineering Faculty, Queensland \\ University of Technology (QUT), Brisbane, Queensland, Australia.
}

\begin{abstract}
This study provided new insights regarding the energy efficiency of hollow fibre forward osmosis modules for seawater desalination; and as a consequence an approach was developed to improve the process performance. Previous analysis overlooked the relationship between the energy efficiency and operating modes of the hollow fibre forward osmosis membrane when the process was scaled-up. In this study, the module length and operating parameters were incorporated in the design of an energy-efficient forward osmosis system. The minimum specific power consumption for seawater desalination was calculated at the thermodynamic limits. Two FO operating modes: (1) draw solution in the lumen and (2) feed solution in the lumen, were evaluated in terms of the desalination energy requirements at a minimum draw solution flow rate. The results revealed that the operating mode of the forward osmosis membrane was important in terms of reducing the desalination energy. In addition, the length of the forward osmosis module was also a significant factor and surprisingly increasing the length of the forward osmosis module was not always advantageous in improving the performance. The study outcomes also showed that seawater desalination by the forward osmosis process was less energy efficient at low and high osmotic draw solution concentration and performed better at 1.2 to $1.4 \mathrm{M}$ sodium chloride draw solution concentrations. The findings of this study provided a platform to the manufacturers and operators of hollow fibre forward
\end{abstract}


osmosis membrane to improve the energy efficiency of the desalination process.

Keywords: Energy efficiency; Desalination energy; Forward Osmosis; Hollow Fibre Membrane; Seawater

\section{Introduction}

Osmotically driven membrane processes have been proposed for water purification and seawater desalination [1], as an alternative to classical membrane filtration processes such as Reverse Osmosis (RO) [2, 3] and Nanofiltration (NF) [4] technologies. For example, there is a wealth of literature regarding Forward Osmosis (FO), which has provided substantial information about potential process applications and limitations $[5,6]$. As a consequence, FO has been recommended for seawater desalination due to claims that it is more energy efficient and capable to deal with a wide range of feed salinities [7]. Typically, FO desalination plant consists of two stages; i.e. a low pressure osmotically driven FO stage and an energy intensive regeneration stage. The purpose of the FO stage is to extract fresh water from seawater by a preengineered ionic solution of known composition and concentration, called the draw solution [8]. In the regeneration stage, which is the most energy-intensive separation process in the FO unit, freshwater is extracted from the draw solution by membrane or thermal technologies [5]. Although FO pre-treatment increases the capital and operating cost of the desalination plant, it can be justified due to the improvedperformance of the downstream regeneration stage [9]. When it is coupled with the RO membrane, FO pre-treatment will reduce fouling of the RO membrane, minimizes chemicals use, increases RO recovery rate, and minimizes the downtime of the RO system [10].

Commercial FO membranes are currently available in spiral wound, flat sheet, and hollow fibre configurations $[11,12]$. Hollow fibre FO (HF-FO) membranes have gained in popularity because of their high packing density and mechanical strength.

\footnotetext{
*Corresponding author

Email address: ali.altaee@uts.edu.au
} 
Nevertheless, water transport phenomenon from the feed to the draw solution in a full-scale HF-FO module is more complicated than in a laboratory-size flat sheet membrane due to the dynamic changes in the concentrations of feed and draw solution along the module [12]. Moreover, the energy requirements in the regeneration stage are directly impacted by the concentration and flow rate of the draw solution $[6,9]$. In an ideal FO process, the concentration of diluted draw solution at the outlet of FO module should be close to that of the seawater while the flow rate of the draw solution should be optimized to reduce the pretreatment and pumping energy [13]. It is agreed that increasing the flow rate of the draw solution reduces the effect of concentration polarization; but this process also increases the concentration of diluted draw solution and adversely affects the energy efficiency in the regeneration stage $[9,14]$. Furthermore, the required energy for pumping the feed and draw solutions into the hollow fibre FO module is dependent on their flow direction; i.e. shell or lumen side. The energy required for pumping solutions in the lumen side is usually greater than that in the shell side because of the higher pressure drop in the lumen side, leading to a hydraulic pressure gradient across the FO membrane module. As such, optimization of the FO process for seawater desalination should consider the flow direction of both feed and draw solutions. Notably, this outlined issue has not been taken into account in previous studies, potentially creating a misunderstanding about the potential and performance of the FO process in seawater desalination.

Another aspect, which may restrict our understanding of forward osmosis, is the fact that the majority of previous FO studies focused on a laboratory-scale flat sheet membrane unit; while there were comparatively few studies on a full-scale FO module $[8,15]$. Consequently, there are gaps in our understanding concerning issues, which become apparent only when you upscale the membrane system. Masafumi et al. [16] proposed use of a Toyobo hollow fibre FO membrane with an effective area of $70 \mathrm{~m}^{2}$, to investigate the impact of membrane orientation and inlet flow rate on the performance of FO process. This study proposed using lower inlet flow rate in order to operate with high-energy efficiency. However, this approach will increase the membrane area and hence the cost of FO treatment. In addition, this study 
investigated neither the desalination energy nor the optimum FO module length. A laboratory scale experiment by Ren and McCutcheon [11] evaluated the performance of a biomimetic hollow fibre using a $1 \mathrm{M}$ draw solution and a deionized water feed solution. The study reported $21 \mathrm{~L} / \mathrm{m}^{2} \mathrm{~h}$ water flux and $0.18 \mathrm{~g} / \mathrm{L}$ reverse salt flux in the PRO mode; but it did not investigate the energy requirements for desalination. Dinesh et al. [17] investigated the energy saving by incorporating a hollow fibre FO membrane with a RO membrane as a hybrid system. FO hybridization with the RO unit resulted in $25 \%$ specific energy saving compared to the conventional RO system. Unfortunately, the study did not investigate FO module optimization and impact of module length on the energy requirements for desalination. Chun and Tai-Shung [18] performed a techno-economic study on FO integration with an RO system to reduce the energy consumption of seawater desalination. This study concluded that the desalination energy could be reduced from 1.95 to $1.83 \mathrm{kWh} / \mathrm{m}^{3}$ and $1.47 \mathrm{kWh} / \mathrm{m}^{3}$ by RO-FO and FO-RO systems, respectively. Nevertheless, this study did not investigate the effect of FO module length or flow orientation upon the power consumption. A pilot plant study by Yasuhiko et al. [19] investigated the impact of operating parameters on the process performance using a $1 \mathrm{M} \mathrm{NaCl}$ draw solution and tap water feed solution. A full-scale hollow fibre FO module which was $0.682 \mathrm{~m}$ long, was investigated to study the impact of hydraulic pressure and flow rate on the process performance. This study concluded that not all the membrane area inside the module was effectively used which resulted in a low water flux. Therefore, it was recommended that a shorter module length should be used to overcome this problem.

Most pilot plant studies used a commercial full-scale FO module, which inherently restricted the ability to discern the impact of module length on the energy efficiency of the process under various operating parameters [7]. Consequently, a problem exists in understanding the relationship between the length of the hollow fibre FO module and the energy requirements for seawater desalination. The energy requirements for seawater desalination by FO process should at least include the minimum energy for separating the fresh water from the draw solution (since the FO process only generates a concentrated saline solution). Therefore, the aim of this 
study was to obtain the optimum physical dimensions of a hollow fibre FO module to reduce the energy requirements for seawater desalination. This study investigated optimization of the operating energy of the hollow fibre FO module that was incurred due to pumping the feed solutions and the impact of membrane orientation on the energy-efficiency of the FO process. The minimum flow rate of the draw solution required for seawater desalination was calculated, for the first time, to reduce the pumping energy into the FO module without compromising the dilution process. We also performed a thermodynamic analysis of the specific power consumption for seawater desalination by the HF-FO modules. The minimum energy required for RO treatment of the draw solution was calculated and added to the energy consumption in the FO process to determine the optimum desalination energy.

\section{Background Theory and Methods}

\subsection{Minimum Draw Solution Flow Rate Requirements}

The minimum draw solution flow rate in the FO process is a critical parameter, which controls the performance and efficiency of the FO process [14]. Increasing the flow rate of the draw solution promotes the mixing regime in the bulk solution and reduces the effect of dilutive concentration polarization. On the other hand, greater flow rate increases the osmotic pressure of the draw solution going to the RO regeneration system [Appendix Figure 1A]. Unfortunately, this situation will increase the energy required for separating the fresh water in the RO regeneration stage [9]. Assuming an ideal counter-current FO process, the concentration of draw solution at the membrane outlet, $C_{d o}$, should be equal to that of the feed solution at the membrane inlet, $C_{f i}$, so that the desalination energy is at its thermodynamic limits [13] [Equation 1].

Equation 1: $\quad C_{d o}=C_{f i}$

The bulk concentration of draw solution, $C_{d b}$, is the average concentration of draw solution at the inlet and outlet of the membrane [Equation 2]. 
Equation 2: $\quad C_{d b}=\frac{C_{d i}+C_{f i}}{2}$

Where, $C_{d i}$ is the concentration of draw solution at the inlet of the membrane. The concentration of the feed solution becomes more concentrated along the FO membrane due to the fresh water transport across the membrane. The concentration of feed solution at the membrane outlet, $C_{f o}$, is a function of the feed concentration at the inlet of the membrane and the recovery rate, $\mathrm{R}$ [Equation 3].

Equation 3: $\quad C_{f o}=\frac{C_{f i}}{1-R} \quad$ [3]

However, the recovery rate in the FO process is related to the ratio of permeate to feed flow rate, and taking this factor into account we can derive Equation 4.

Equation 4: $\quad C_{f o}=\frac{C_{f i} Q_{f i}}{Q_{f i}-Q_{p}}$

Where, $Q_{f i}=$ flow rate of feed $(\mathrm{L} / \mathrm{h})$ and $Q_{p}=$ flow rate of permeate $(\mathrm{L} / \mathrm{h})$

The bulk concentration of feed solution, $C_{f b}$, is the average concentration of feed solution at the inlet and outlet of the membrane [Equation 5].

Equation 5: $\quad C_{f b}=\frac{C_{f i}+C_{f o}}{2}$

Replacement of $C_{f_{o}}$ in Equation 5 with the expression from Equation 4 gives Equation 6:

Equation 6: $\quad C_{f b}=\frac{2 C_{f i} Q_{f i}-C_{f i} Q_{p}}{2\left(Q_{f i}-Q_{p}\right)}$

In an osmotically-driven membrane processes, the concentration of feed and draw solution at the membrane surface is equal to $C_{f b}$, and $C_{f b}$ multiplied by the moduli of 
concentrative and dilutive concentration polarization, respectively. Permeate flow rate in the FO process operated with the membrane active layer contacting the feed solution (FS-AL) and the membrane layer contacting the draw solution (DS-AL), is expressed in Equations 7a and 7b, respectively.

Equation 7 (a): $\quad Q_{p f}=A_{w} \frac{n R T C_{d b} \exp \left(\frac{-Q_{p f} K}{A}\right)-n R T C_{f b} \exp \left(\frac{Q_{p f}}{A k}\right)}{1+\frac{B A}{Q_{p f}}\left(\exp \left(\frac{Q_{p f}}{A k}\right)-\exp \left(\frac{-Q_{p f} K}{A}\right)\right)}$

Equation 7 (b): $\quad Q_{p d}=A_{w} \frac{n R T C_{d b} \exp \left(\frac{-Q_{p f}}{A k}\right)-n R T C_{f b} \exp \left(\frac{Q_{p f} K}{A}\right)}{1+\frac{B A}{Q_{p f}}\left(\exp \left(\frac{Q_{p f} K}{A}\right)-\exp \left(\frac{-Q_{p f}}{A k}\right)\right)}$

Where: $A_{w}$ is the water permeability coefficient; $B$ is the salt diffusion coefficient; $n$ is number of ions in solution; $R$ is the gas constant; $A$ is FO membrane area; $k$ is the mass transfer coefficient; and, $K$ is the solute resistivity for diffusion within the porous support layer. Equations $7 \mathrm{a}$ and $7 \mathrm{~b}$ calculate permeate flow rate in the FO membrane that accounts for the concentration polarization effects; and hence, provides a more accurate estimate to the permeate flow rate. Considering the mass and flow balance on the draw solution side of the FO membrane (assuming an ideal FO membrane with a complete solute rejection), we get Equation 8.

Equation 8: $\quad Q_{d i} C_{d i}=C_{d o} Q_{d o}$

Where, $Q_{d i}$ and $Q_{d o}$ are the flow rates of the draw solution at the inlet and outlet of the membrane, respectively. The flow rate of draw solution at the outlet of the membrane, $Q_{d o}$, is equal to the flow rate of draw solution at the inlet of the membrane plus the permeate flow rate from the feed to the draw solution; i.e. $Q_{d o}=Q_{d i}+Q_{p}$. Replacing $Q_{d o}$ in Equation 8 with this expression gives Equation 9.

Equation 9: $\quad Q_{d i}=\frac{C_{d o} Q_{p}}{C_{d i}-C_{d o}}$

Equation 9 calculates the flow rate of the draw solution at the inlet of the FO module 
as a function of the concentration of draw solution and permeate flow rate. According to Equation 1 , the energy required for desalination of the draw solution, $C_{d o}$, will be equal to the minimum energy required by thermodynamics when the concentration of draw solution at the membrane outlet is equal to the concentration of seawater feed solution; i.e. $C_{d o}=C_{f 1}$.

To illustrate what these models mean, consider the example where we have a $400 \mathrm{~L} / \mathrm{h}$ feed flow rate. The flow rate of the draw solution at the inlet $\left(Q_{d i}\right)$ decreased from 129 to $73 \mathrm{~L} / \mathrm{h}$ as the draw solution concentration increased from 0.8 to $2.4 \mathrm{M}$ (Figure $1 \mathrm{~A}$ ). Simulation results show that the flow rate of the draw solution was lower than that of the feed solution $(\sim 400 \mathrm{~L} / \mathrm{h})$ at all draw solution concentrations. The results also show that $Q_{d i}$ in the FO process operating in DS-AL mode was greater than that in the FO process operating in FS-AL mode (Figure 1A). This behaviour was due to the higher permeate flow in the FO process operating in the DS-AL that triggered, slightly, higher draw solution flow rate to maintain the permeate flow rate across the membrane (Figure 1B) [20]. The flow rates of draw solution in Figure 1A were used as input values when calculating the pressure drop and water flux in a module-scale FO membrane.
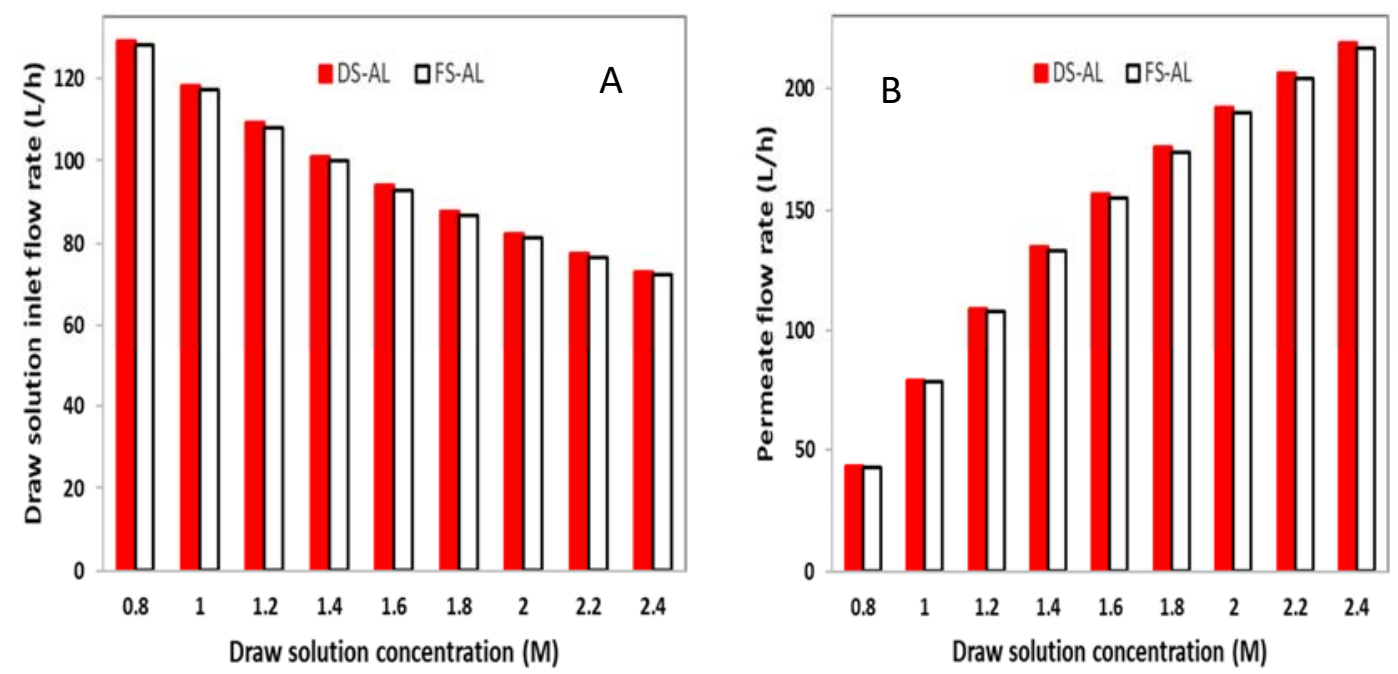

Figure 1: Draw solution flow rate at outlet of the FO membrane and permeate flow rate. Feed flow rate, $Q_{f i}$, is $400 \mathrm{~L} / \mathrm{h}$, feed concentration is $0.6 \mathrm{M} \mathrm{NaCl}$ (representing seawater), feed solution is $0.02 \mathrm{M} \mathrm{NaCl}$ (representing wastewater) for $0.6 \mathrm{M}$ draw solution, and FO membrane area is $20 \mathrm{~m}^{2}$. 


\subsection{Direction of Hydraulic Pressure in the FO Module}

Obtaining the energy requirement for pumping the feed and draw solution in the FO module is important in relation to understanding the energy efficiency of the FO process. Energy requirements for pumping the feed and draw solutions into the HFFO module substantially varies with the module length and flow direction of the feed and draw solution; i.e. draw solution in the lumen (DS-lumen) or feed solution in the lumen (FS-lumen). Pressure drop in the lumen is higher than that in the shell side of the HF-FO membrane, and hence the hydraulic pressure in the lumen side will be greater $[16,18]$. As a result, a hydraulic pressure gradient will develop across the FO membrane. The amount of net hydraulic pressure depends on the length of the FO module and the solutions flow rates. The net hydraulic pressure across the membrane will be either with or opposite to the flow direction of the permeate flow; this depends on whether the FO operates in DS-lumen or FS-lumen mode. Pumping energy, in general, is a function of the hydraulic pressure and the solution flow rate [9]. Although Figure $1 \mathrm{~A}$ shows that the flow rate of the feed solution in the FO process was greater than that of the draw solution, it was useful to further demonstrate this principle mathematically.

In order for draw solution to be sufficiently diluted, previous studies suggested that $C_{d o}$ should be equal to $C_{f 1}$; i.e. $C_{d o}=C_{f 1}[13]$. Replacement of this expression in Equation 8 gives Equation 10.

Equation 10: $\quad Q_{d i} C_{d i}=C_{f i} Q_{d o}$

Equation 10 can be expressed in terms of the initial concentration of feed solution, $C_{f i}$ and $Q_{d o}=Q_{d i}+Q_{p}$ [Equation 11].

Equation 11: $\quad C_{f i}=\frac{Q_{d i} * C_{d i}}{\left(Q_{d i}+Q_{p}\right)}$ 
Equation 4 also can be expressed in terms of $C_{f i}$ and $Q_{f o}=Q_{f i}-Q_{p}$ [Equation 12].

Equation 12: $\quad C_{f i}=\frac{C_{f o} * Q_{f o}}{Q_{f i}}$

Combining Equations 11 and 12, and expression the final equation in terms of $Q_{d i}$ [Equation 13].

Equation 13: $\quad Q_{d i}=\frac{C_{f o} * Q_{f o} * Q_{p}}{Q_{f i} * C_{d i}-C_{p} * Q_{f o}}$

Equation 13 calculates the flow rate of the draw solution as a function of the flow rate of the feed solution. Using draw solution concentrations ranging from 1.0 to $2.4 \mathrm{M}$ and $0.6 \mathrm{M}$ feed solution (equivalent to seawater concentration), the flow rate of draw solution for different recovery rates was as shown in Figure $2 \mathrm{~A}$.

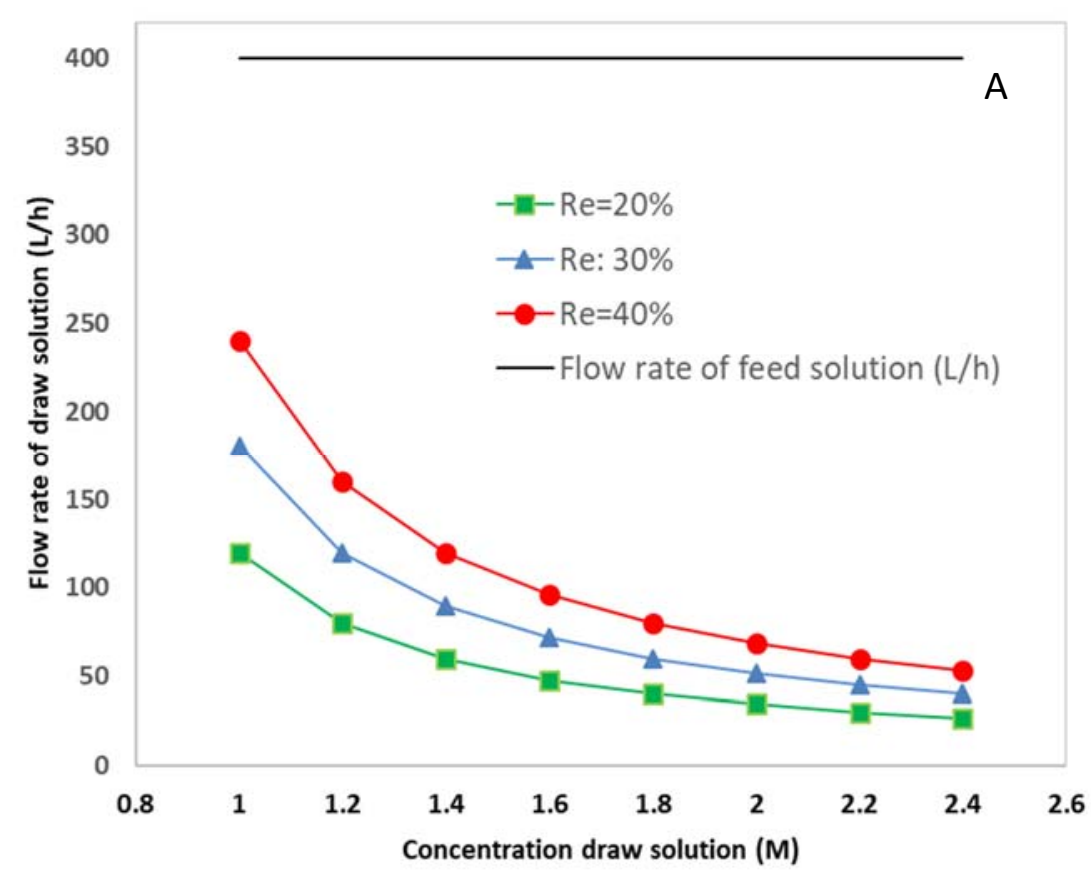




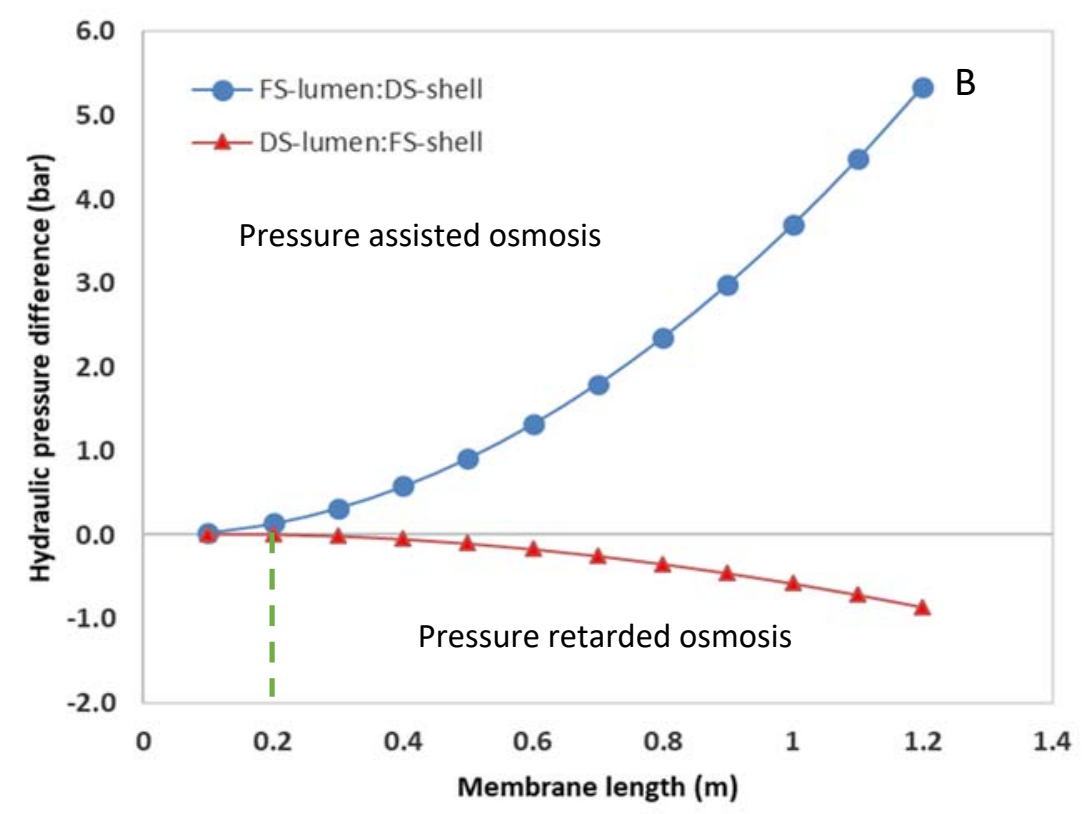

Figure 2: A) draw solution flow rate in the FO membrane with respect to the concentration of draw solution; flow rate of the feed solution was $400 \mathrm{~L} / \mathrm{h}$; B) impact and direction of hydraulic pressure along the HF-FO membrane where the dashed line separated PAFO and PRO modes when the FO operated in DS-lumen:FS-shell mode: 1.6 - $0.6 \mathrm{M}$ salinity gradient resource; feed and draw solutions' flow rates were 400 and $95 \mathrm{~L} / \mathrm{h}$, respectively; membrane area was $20 \mathrm{~m}^{2}$.

As highlighted in Figure 2A, the flow rate of the draw solution decreased gradually when increasing the concentration of draw solution. For a given draw solution concentration, increasing the recovery rate from 20 to $40 \%$ required increasing of the flow rate for the draw solution; this approach allowed the FO process to overcome the effect of dilutive concentration polarization. Regardless of the FO testing conditions, the results revealed that the flow rate of the feed solution was larger than that of the draw solution. This data suggested that the energy required for pumping the feed solution into the FO module was greater than that for pumping the draw solution (since pumping energy is a function of hydraulic pressure and solution flow rate).

The minimum pumping energy in the HF-FO membrane should be at least equal to the pressure drop in lumen or shell side, depending on the direction of solution flow. Typically, pressure drop in the lumen side, $d P_{l}$, is expressed by the Hagen-Poiseuille 
equation [21] [Equation 14].

Equation 14: $\left.\quad \frac{d p_{l}}{d x}=\frac{128 \mu Q_{l}}{\pi d_{i}^{4}}\right]$

Where: $x$ is the axial coordinate that corresponds to the axial direction of the HF bundle; $\mu$ is the viscosity of the lumen side solution (pa.s); $Q_{l}$ is the flow rate of the lumen side solution $\left(\mathrm{m}^{3} / \mathrm{s}\right)$; and, $d_{i}$ is the inner diameter of the hollow fibre $\{\mathrm{m})$. Pressure drop on the shell side of the HF-FO membrane, $d P_{s}$, can be expressed by the Ergun equation [21] [Equation 15].

Equation 15: $\quad \frac{d p_{s}}{d r}=\frac{150 \sigma^{2} \mu V_{S}}{(1-\sigma)^{3}\left(1.5 d_{o}\right)^{2}}+\frac{1.75 \sigma \rho V_{S}^{2}}{(1-\sigma)^{3}\left(1.5 d_{o}\right)}$

Where: $r$ is the radial coordinate; $\sigma$ is the packing density of fibre bundle; $\mu$ is viscosity of shell side solution (pa.s); Vs is the superficial velocity within the fibre bundle $(\mathrm{m} / \mathrm{s})$; and, $d_{o}$ is the outer diameter of the hollow fibre $(\mathrm{m})$. The $d_{i}$ and $d_{o}$ values for the hollow fibre were assumed to be 135 and $175 \mu$, respectively. This study assumed the FO membrane active area is equal to $20 \mathrm{~m}^{2}$ and packing density was $55 \%$ [21]. Table 1 shows the technical specifications of the hollow fibre FO module. According to Equations 14 and 15, the pressure drop in the FO membrane increased with: (i) the length of the module (ii) smaller inner diameter in the lumen-side, and (iii) higher solution flow rate. As a result, a net hydraulic pressure developed either in the same or opposite direction to the permeate flow depending on the operating mode of the FO membrane; i.e. FS-lumen or DS-lumen. An FO process with a net hydraulic pressure in the direction of permeate flow is known as pressure assisted FO (PAFO) while it is called pressure retarded osmosis (PRO) when the net hydraulic pressure is in an opposite direction to the permeate flow. 
Table 1: Specifications of the hollow fibre FO module

\begin{tabular}{|c|c|c|c|c|}
\hline $\begin{array}{c}\text { Inner diameter, } \\
d i, \text { of } \mathrm{HF}(\mu \mathrm{m})\end{array}$ & $\begin{array}{c}\text { Outer diameter, } \\
d o, \text { of } \mathrm{HF}(\mu \mathrm{m})\end{array}$ & $\begin{array}{c}\text { Membrane area } \\
\left(\mathrm{m}^{2}\right)\end{array}$ & HF length $(\mathrm{m})$ & $\begin{array}{c}\text { Packing } \\
\text { density } \%\end{array}$ \\
\hline 175 & 135 & 20 & $0.2-1.2$ & 55 \\
\hline
\end{tabular}

The impact of FO operating mode on the direction of the hydraulic pressure is illustrated in Figure 2B. When the FO operated in the DS-lumen mode, the hydraulic pressure across the FO membrane was in the direction of the permeate flow and the FO membrane operated in the PAFO mode for module lengths from 0.1 to $0.2 \mathrm{~m}$ (Figure 2B). This behaviour was because of the greater hydraulic pressure of the shell solution compared to that of the lumen solution. At an FO module length from 0.3 to $1.2 \mathrm{~m}$, the net hydraulic pressure switched its direction and the FO membrane operated in the PRO mode. In another words, the hydraulic pressure in the lumen became greater than that in the shell at FO module length $>0.3 \mathrm{~m}$ and thus the FO operated in the PRO mode since the hydraulic pressure was opposite to the direction of the permeate flow. Therefore, the operating mode of the FO module changed along the FO module and it could be: in the same direction of the permeate flow; PAFO mode; or opposite to the direction of the permeation flow, PRO mode, depending on the membrane length. FO modules less than $0.3 \mathrm{~m}$ long, for example, will operate in the PAFO mode in which the hydraulic pressure was in the direction of the permeate flow. Whilst for 0.3 to $1.2 \mathrm{~m}$ long FO modules, the hydraulic pressure will be against the direction of the permeate flow and the module operated in the PRO mode.

On the other hand, when the draw solution was in the shell and feed solution in the lumen side, the FO module operated in the PAFO mode for module lengths from 0.1 to $1.2 \mathrm{~m}$ (Figure 2). In this scenario, the high flow rate feed solution was pumped in the lumen side of the FO membrane. A net hydraulic pressure (0.03 to $5.3 \mathrm{bar}$ ) was developed in the direction of the permeate flow and it increased with an increase in the module length. This is because the hydraulic pressure required to pump the feed solution into the lumen was greater than that required to pump the draw solution into the shell of the HF-FO module. 
Although PAFO operating mode promotes water flux across the FO membrane, it is usually associated with an increase in the energy requirements of the FO process. In general, the hydraulic pressure required for pumping solutions in the lumen side is higher than that required for pumping solution in the shell side and it increases with an increase in solution flow rate. The greater hydraulic pressure in the FS-lumen mode is attributed to the high flow rate of the feed solution that requires higher pressure to pump in the hollow fibres. This scenario also suggests that the flow direction of the feed and draw solution will affect the desalination energy of the FO process (discussed below).

\subsection{Desalination energy requirement in FO module}

The energy requirements for seawater desalination in the FO-RO process have been addressed in previous literature. Key components include: seawater pre-treatment energy; pumping energy of feed and draw solutions into the FO module; and, RO regeneration energy $[5,22]$. Mathematically, FO energy, $E_{F O}$, can be obtained from Equation 16.

Equation 16: $\quad E_{F O}=\frac{Q_{f i} * P_{f i}+Q_{d i} * P_{d i}}{Q_{p}}$

Where: $Q_{f i}$ and $Q_{d i}$ are the flow rates of feed and draw solution $\left(\mathrm{m}^{3} / \mathrm{h}\right)$; respectively, $P_{f i}$ and $P_{d i}$ are the hydraulic pressure on the feed and draw solution side of the membrane (bar), respectively; and, $Q_{p}$ is the permeate flow rate $\left(\mathrm{m}^{3} / \mathrm{h}\right)$. In Equation 16 , the minimum hydraulic pressure required for pumping the solutions was equal to the pressure drop in the lumen and shell side of the FO [Equations 14 and 15]. Substituting Equations 14 and 15 in Equation 16 resulted in equations $17 \& 28$.

Equation 17: $\quad E_{F O-F l}=\frac{Q_{f i} * d P_{l}+Q_{d i} * d P_{S}}{Q_{p}}$

Equation 18: $\quad E_{F O-D l}=\frac{Q_{f i * d P_{S}+Q_{d i} * d P_{l}}}{Q_{p}}$ 
Equations 17 and 18 represent specific energy consumption in the FO membrane with feed solution in the lumen $\left(E_{F O-F I}\right)$ or with draw solution in the lumen $\left(E_{F O-D I}\right)$ side, respectively. In an FO membrane with a given lumen diameter and packing density, the $d P_{l}$ and $d P_{s}$ values vary with the membrane length and the solution flow rate; resulting in an increase in the pumping energy as per Equation 17 and 18 . Therefore, the impact of the FO module length on the energy-efficiency of the desalination process should be evaluated. Water flux in the FO membrane depends on the membrane orientation; i.e. (a) draw solution faces the active layer (DS-AL) and (b) feed solution faces the active layer (FS-AL modes) according to Equations 19 \& 20 [23-24].

Eq. 19 (a) : $J_{w x, f}=A_{w}\left\{\frac{\left(n R_{S} T C_{d i, x}\left(1+\frac{Q_{d i, x}}{Q_{d o, x}}\right) / 2\right) \exp \left(-J_{w, x} K\right)-n R_{s} T C_{f i, x}\left(1-\frac{Q_{f i . x}}{Q_{f o, x}}\right) \exp \left(\frac{J_{w, x}}{k_{f}}\right)}{1+\frac{B}{J_{w, x}}\left(\exp \left(\frac{J_{w, x}}{k_{f}}\right)-\exp \left(-J_{w, x} K\right)\right)}\right\}$

Eq. 19 (b): $J_{w x, d}=A_{w}\left\{\frac{\left(n R_{s} T_{d i, x}\left(1+\frac{Q_{d i, x}}{Q_{d o, x}}\right) / 2\right) \exp \left(\frac{-J_{w, x}}{k_{d}}\right)-n R_{s} T_{f i, x}\left(1-\frac{Q_{f i . x}}{Q_{f o, x}}\right) \exp \left(J_{w, x} K\right)}{1+\frac{B}{J_{w, x}}\left(\exp \left(J_{w, x} K\right)-\exp \left(\frac{-J_{w, x}}{k_{d}}\right)\right)}\right\}$

Where: $J_{w x, f}$ and $J_{w x, d}$ are water flux at distance $x$ along the FO module when feed solution faces the membrane active layer and draw solution faces the membrane active layer $\left(\mathrm{L} / \mathrm{m}^{2} \mathrm{~h}\right)$, respectively; $Q_{d o, x}$ is the outlet flow rate of the draw solution $(\mathrm{L} / \mathrm{h}) ; Q_{d i, x}$ is the inlet flow rate of the draw solution $(\mathrm{L} / \mathrm{h}) ; Q_{f o, n}$ is the outlet flow rate of the feed solution (L/h); $Q_{f i, n}$ is the inlet flow rate of the feed solution; $C_{f i, x}$ is the inlet concentration of the feed solution at the distance $x(\mathrm{M}) ; C_{d i, x}$ is the inlet concentration of the draw solution at the distance $x(\mathrm{M}) ; n$ is number of ions in the solution; $R_{s}$ is the gas constant (L.bar/K.mol); and $T$ is the temperature in Kelvin (K). $A_{w}$ and $B$ were assumed to be $1.23 \mathrm{~L} / \mathrm{m}^{2} \mathrm{~h} \cdot$ bar and $2.6 \mathrm{~kg} / \mathrm{m}^{2} \mathrm{~h}$, respectively. In addition, $K_{d}=k_{f}=0.18$ $\mathrm{m} / \mathrm{h}$, and $K=31 \mathrm{~h} / \mathrm{m}$ [23]. Equation 19 was validated using pilot plant experimental data which employed a hollow fibre FO membrane [supplementary section]. Practically, water flux across the FO membrane dilutes the draw solution and hence would affect the energy requirements for solvent-solute separation in the RO regeneration process. In the RO process, the minimum energy requirements for desalination, $E_{R O}\left(\mathrm{kWh} / \mathrm{m}^{3}\right)$, is calculated from Equation 20 [24]. 
Equation 19: $\quad E_{R O}=\frac{\pi_{d o}}{1-R}$

Where, $R$ is the recovery rate in the RO system. $R$ is ratio of permeate flow rate to the feed flow rate and it should be equal in the FO and RO processes for a continuous FORO system. Equation 20 can also be described as in Equation 21.

Equation 20: $\quad E_{R O}=\frac{\pi_{d o}}{1-\frac{Q_{p}}{Q_{f}}}$

Where, $Q_{p}$ is the permeate flow rate $\left(\mathrm{m}^{3} / \mathrm{h}\right)$ and $Q_{f}$ is the feed flow rate $\left(\mathrm{m}^{3} / \mathrm{h}\right)$. To evaluate the effect module length on the FO performance, feed and draw solution flow rates remained constant for any given concentration of draw solution. The total specific power consumption for desalination, Et, was calculated as the sum of FO and RO processes; $E t=E_{R O}+E_{F O}$. In addition to $E_{R O}$ and $E_{F O}$, there was a pre-treatment energy of the feed solution in the FO membrane. This energy was not included here since the feed flow rate was equal for any given concentration of draw solution.

\section{Results and Discussion}

\subsection{Impact of Flow Direction and Concentration of Draw Solution on Predicted}

\section{Performance of HF-FO Unit}

Concentrated draw solution yields high osmotic flow, but it increases the concentration of draw solution and the separation energy in the regeneration stage. Determining the concentration of draw solution in the FO process requires careful consideration of how to achieve a desirable water flux without compromising the energy of desalination process. Desalination energy is also affected by the flow rate and the flow direction of the feed and draw solution, i.e. shell or lumen side, knowing that the flow rate of feed flow rate is higher than that of the draw solution [Figure $2 \mathrm{~A}$ ]. Membrane orientation also impacts the water flux in the FO membrane; i.e. feed solution faces the active layer (FS-AL) or draw solution faces the active layer (DS-AL) and hence the process performance. Assuming the membrane active layer is in the 
shell side then water flux is greater when the membrane operated in the DS-AL mode $[13,14,25,26]$. However, FO operating in the DS-AL mode means there is a high flow rate feed solution in the lumen and this increases the hydraulic pressure and pumping energy [Figure 2A]. On the other hand, operating the FO in FS-AL mode (FS in the shell side) compromises water flux in the FO process due to the intensive internal concentration polarization effect $[14,25]$; but it reduces the pumping energy since the low flow rate draw solution is in the lumen side. Low water flux in the FS-AL mode had negative consequences on the desalination energy because of the insufficient dilution of the draw solution which means that higher separation energy is required in the regeneration stage. These issues need further investigation to understand the impact of draw solution concentration on the energy of FO seawater desalination.

Calculations were made for a seawater concentration equal to $0.6 \mathrm{M} \mathrm{NaCl}$, draw solution concentrations between 1.0 and $2.4 \mathrm{M}$, and a 1-meter FO module [Figure 3]. For an FO process operating in the DS-lumen mode the specific power consumption for seawater desalination increased gradually from $1.25 \mathrm{kWh} / \mathrm{m}^{3}$ with a $1 \mathrm{M}$ draw solution to $1.75 \mathrm{kWh} / \mathrm{m}^{3}$ for a $2.4 \mathrm{M}$ draw solution [Figure 3A]. Apparently, increasing the concentration of the draw solution from 1 to $2.4 \mathrm{M}$ was not sufficient to achieve an adequate permeate flow to dilute the draw solution [Appendix A.2]. It is emphasised that water flux was expected to be lower when the FO is operating in the DS-lumen mode due to the intensive internal concentration polarization effect [25, 27]. The results indicated that increasing the concentration of draw solution did not necessarily improve the energy-efficiency of the desalination process. For the FO process operating in the FS-lumen mode, the profile of total specific energy (FO plus RO regeneration) was slightly different to that operating in the DS-lumen mode. The total specific energy increased from $1.8 \mathrm{kWh} / \mathrm{m}^{3}$ with a $1 \mathrm{M}$ draw solution to 2.04 $\mathrm{kWh} / \mathrm{m}^{3}$ with a $2.4 \mathrm{M}$ draw solution; but the lowest desalination energy was 1.76 $\mathrm{kWh} / \mathrm{m}^{3}$ at $1.2 \mathrm{M}$ draw solution concentration. Figure $3 \mathrm{~A}$ also shows that power consumption for seawater desalination was greater in the FS-lumen mode because of the higher pressure required for pumping the high flow rate feed solution in the lumen side. The results confirmed the significance of selecting a proper draw solution concentration that improved the energy efficiency of the desalination process. 
Figure $3 \mathrm{~B}$ shows the breakdown of specific power consumption in the FO and RO regeneration unit with respect to the total specific power consumption in the desalination process. Normally, the specific power consumption in the RO regeneration stage was greater with the increase of the draw solution concentration. On the contrary, the specific power consumption in the FO module diminished when increasing the concentration of draw solution in both DS-lumen and FS-lumen modes. This situation was due to: (i) lower flow rate of draw solution with increasing concentration of draw solution [Figure $1 \mathrm{~A}$ ] and (ii) larger permeate flow rate at higher draw solution concentrations [Appendix A.2]. The results also revealed that specific power consumption in the FO module was higher in the FS-lumen mode than in the DS-lumen mode; that observation was mainly due to the higher flow rate and pressure of the feed solution in the FS-lumen [Figure 3B]. Interestingly, for FO operating in the FS-lumen mode and $1 \mathrm{M}$ draw solution, the specific power consumption in the FO and RO processes was similar. This outcome was because of the moderately low energy required in the RO unit, which was almost equal to the energy required for pumping solutions in the FO module. Practically, the energy required for pumping solutions in the lumen is higher than that in shell side and it increases with increasing flow rate of solution. Therefore, the FS-lumen mode consumed more energy than the DS-lumen mode; but it is recommended in the FO modules to have an active layer in the lumen side to decrease the extent of membrane fouling [28, 29]. 

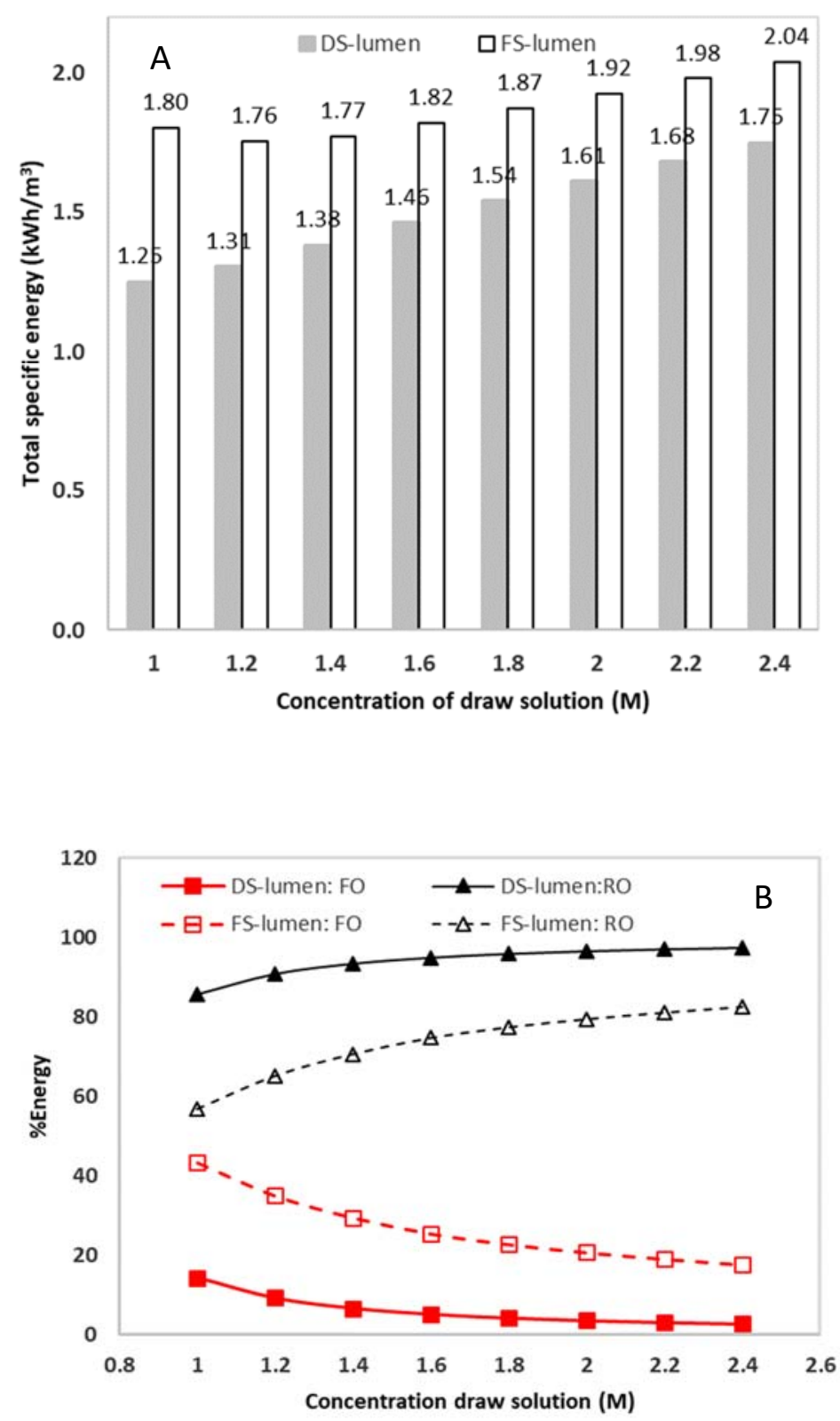

Figure 3: Energy requirements in the FO and RO process for seawater desalination A) total specific power consumption in the FO-RO system B) percentage of FO and RO specific power consumption when FS-lumen \& DS-lumen, module length is 1 meter

\subsection{Feed solution in lumen side in HF-FO module}

Water flux in osmotically driven processes is greater when the draw solution faces the membrane active layer, i.e. DS-AL. Practically, external concentration polarization is easier to control than internal concentration polarization $[27,30]$. For the HF-FO membrane with an outer active layer (in the shell side) to operate in the FS-AL mode, it requires the feed solution to be in the lumen side, FS-lumen. The drawback of FS- 
lumen mode is the high energy required for pumping the high flow rate feed solution in the lumen side. In practice, the flow rate of feed solution is dynamically changing along the FO module due to the water flux across the membrane. For seawater desalination, it is the concentration of the draw solution that controls the osmotic pressure and water flux across the FO membrane. To effect a fair comparison, the flow rates of the feed and draw solution remain constant, regardless of the length of the FO module.

The total power consumption for seawater desalination varied along the FO module and it increased with an increase in the length of the FO module (from 0.2 to $1.0 \mathrm{~m}$ ) due to the greater hydraulic pressure required for pumping the solutions in the FO module [Figure 4A]. Performance of the FO module also varied, depending on the concentration of the draw solution; showing that for some draw solution concentrations there was an optimal module length at which the power consumption of desalination was reduced. For a $1.6 \mathrm{M}$ draw solution, the desalination power consumption was $1.6 \mathrm{kWh} / \mathrm{m}^{3}$ in a $0.2 \mathrm{~m}$ long $\mathrm{FO}$ module but decreased to 1.55 $\mathrm{kWh} / \mathrm{m}^{3}$ in a $0.4 \mathrm{~m}$ long FO module. Subsequently, the power reached $1.8 \mathrm{kWh} / \mathrm{m}^{3}$ in a $1 \mathrm{~m}$ long FO module. This behaviour was due to the combined effects of the low pumping energy and large permeation flow in the FO module of $0.4 \mathrm{~m}$ long that reduced desalination power consumption [Appendix A.2]. As the length of the FO module increased, the energy for pumping the solutions in the module increased. While the small permeation flow resulted in a limited dilution of the draw solution, the overall effect was an increase in the desalination power consumption. The trends in desalination power consumption with a $1.4 \mathrm{M}$ draw solution were similar to those for a 1.6M draw solution; but the lowest desalination power consumption was 1.45 $\mathrm{kWh} / \mathrm{m}^{3}$ in a $0.3 \mathrm{~m}$ long FO module, which then increased to $1.77 \mathrm{kWh} / \mathrm{m}^{3}$ in a $1 \mathrm{~m}$ long FO module. For 1.0 and $1.2 \mathrm{M}$ draw solutions, the desalination power consumption increased with greater length of the FO module and reached 1.80 and $1.75 \mathrm{kWh} / \mathrm{m}^{3}$ in $1 \mathrm{~m}$ FO module operated with 1.0 and $1.2 \mathrm{M}$ draw solution, respectively.

The results in Figure $4 \mathrm{~A}$ revealed that the desalination energy was almost the same in 
a $1.0 \mathrm{~m}$ long FO module despite the large difference in the concentration of draw solution and the osmotic driving force. The high desalination energy requirements in the $1.0 \mathrm{M}$ draw solution were due to the relatively large draw solution flow rate, which increased the pumping energy of solutions in the FO process. Using low concentration draw solutions required a high flow rate to maintain the permeate flow across the FO membrane. The results also revealed that the length of the FO module should preferably be equal to or less than $0.7 \mathrm{~m}$ with a $1.0 \mathrm{M}$ draw solution. As the length of the FO module increased to more than $0.7 \mathrm{~m}$, the desalination energy for a $1.0 \mathrm{M}$ draw solution was slightly more than that for $1.2 \mathrm{M}$ draw solution. In another words, using a 1.2 M draw solution was more energy efficient than a $1.0 \mathrm{M}$ draw solution for a FO module more than $0.7 \mathrm{~m}$ long; and hence using a $1.0 \mathrm{~m}$ long FO module will not always result in a more energy-efficient desalination process. The impact of draw solution concentration on the power consumption of seawater desalination should be accounted for in an efficient desalination process.

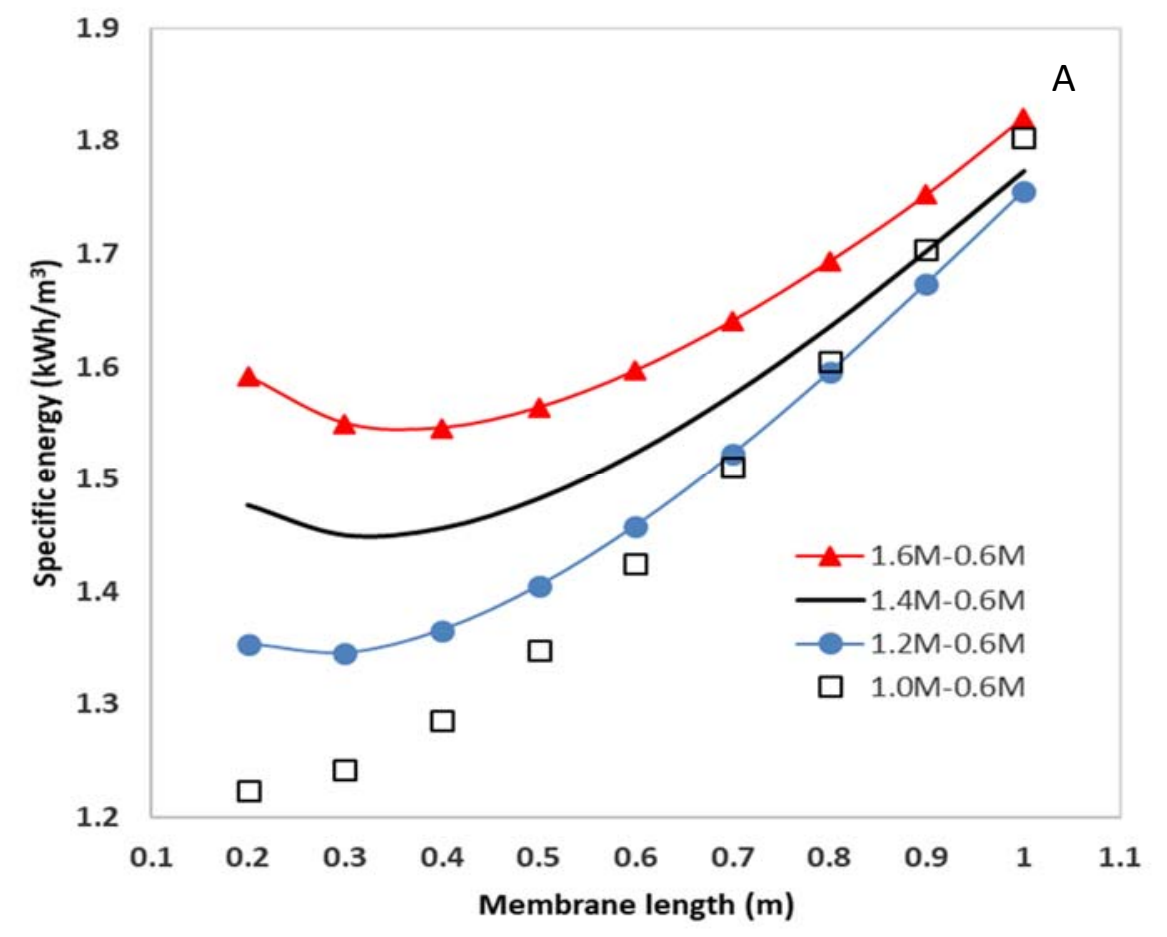




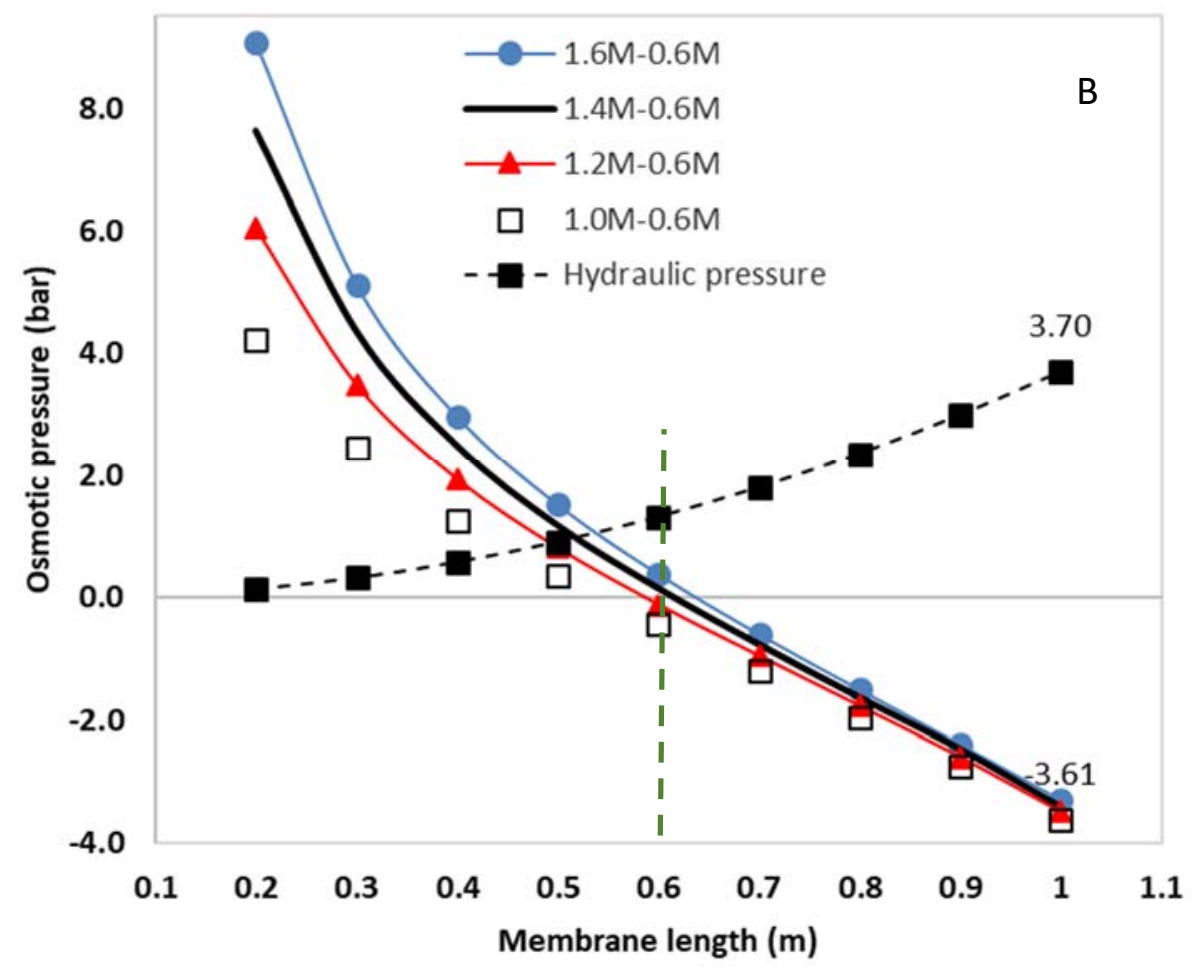

Figure 4: Impact of the length of the FO module on A) the total specific power consumption of the desalination B) the osmotic pressure along FO module of different lengths, feed water is $0.6 \mathrm{M} \mathrm{NaCl}$ and feed flow rate is $400 \mathrm{~L} / \mathrm{h}$, feed and draw solution flow rates are equal in any given draw solution concentration.

In the HF FO membrane, water flux occurs: primarily due to the osmotic pressure gradient across the membrane; and secondary because of the hydraulic pressure difference across the membrane when $P_{f}>P_{d}$. Figure $4 \mathrm{~B}$ shows that the osmotic pressure driving force diminished gradually with the increase of the FO module length due to the dilution and concentration of the draw and feed solutions, respectively. Subsequently, the driving force then reached almost zero with a $0.6 \mathrm{~m}$ long FO module. For FO modules $\leq 0.6 \mathrm{~m}$ long, the driving force in the FO process was a combination of osmotic and hydraulic pressures. However, hydraulic pressure became the main driving force in FO modules $>0.6 \mathrm{~m}$ long, and this phenomenon was responsible for the low permeation flow in the FO operating in the FS-lumen mode. Furthermore, Figure $4 \mathrm{~B}$ suggested that membrane length should be equal to or less than $0.6 \mathrm{~m}$ for an energy-efficient FO process operating in the FS-lumen mode. 
Desalination energy, apparently, increases sharply in FO modules longer than $0.6 \mathrm{~m}$ due to the increase in the pumping energy and insignificant dilution of draw solution towards the end of the FO modules [Figure 4A]. It is noteworthy that there is no large difference in the hydraulic pressure gradient across the membrane for FO modules having equal length since changing the concentration of the draw solution is slightly affecting the flow rate of the draw solution as illustrated in Figure 1.

\subsection{Draw solution in lumen side in HF-FO module}

Hollow fibre FO membranes operate with the draw solution in the lumen side (DSlumen) and with the feed solution in the shell side [16]. Fouling of the FO membrane is considered to be more controllable when the feed solution faces the membrane active layer (which is assumed to be in the shell side in this study). Similar flow rates of the feed and draw solution were used to evaluate the specific power consumption on the performance of the FO modules between 0.2 and $1.0 \mathrm{~m}$ long. The specific power consumption profile for seawater desalination indicated that the energy efficiency of the FO process changed with the length of the FO module [Figure 5A].

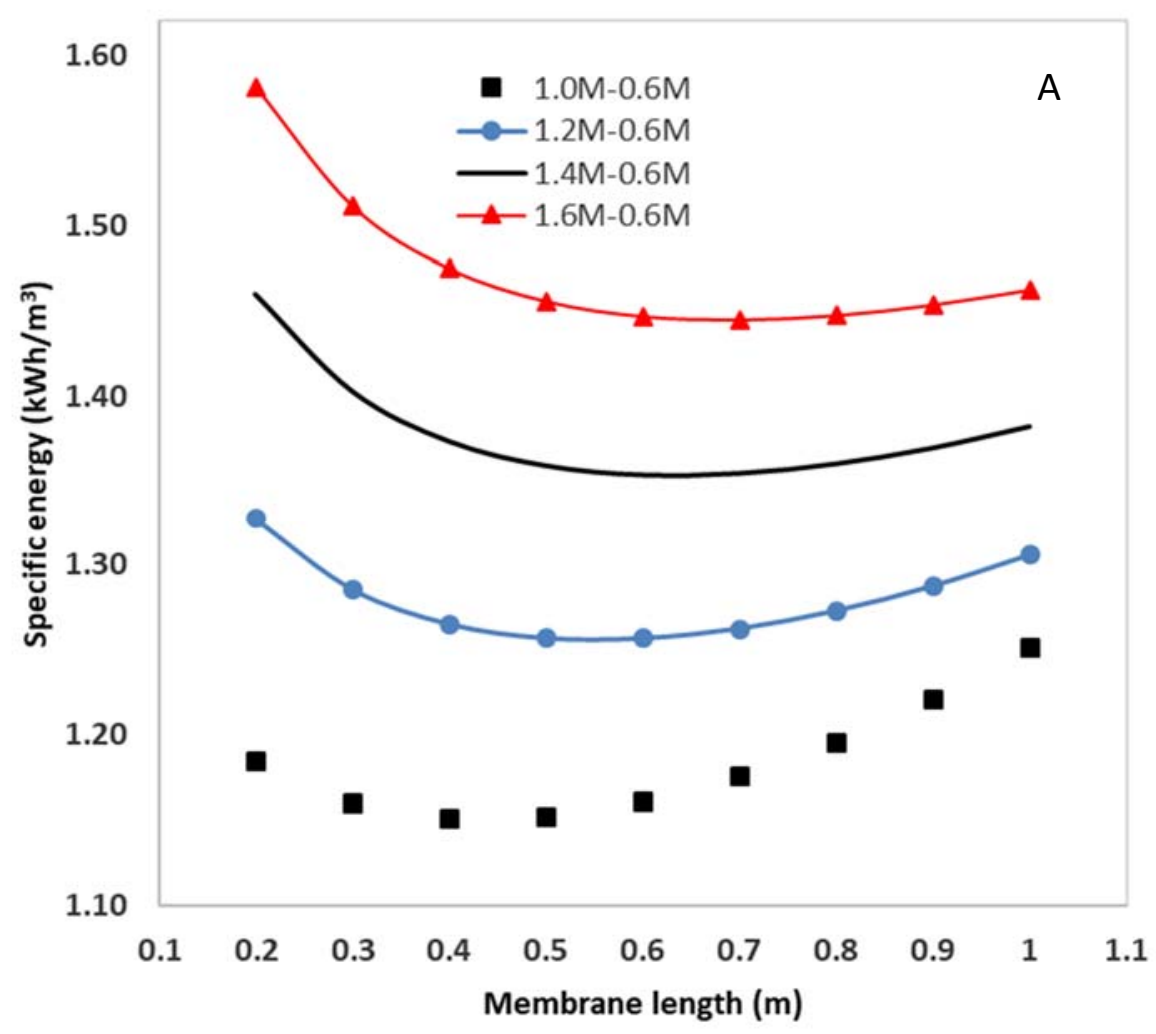



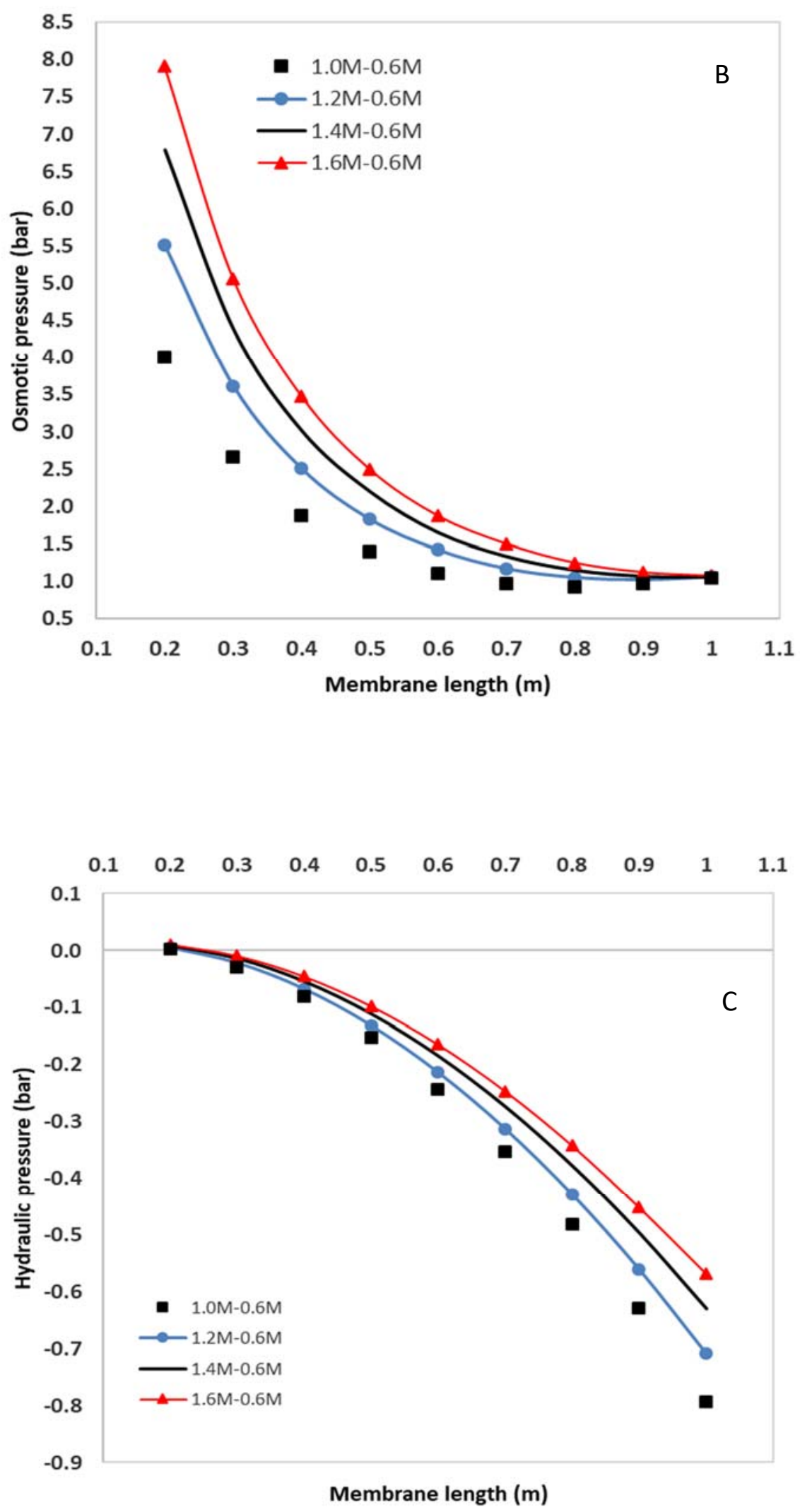

Figure 5: The specific power consumption for seawater desalination by the FO process operating in DS-lumen mode A) total specific power consumption for seawater desalination using FO module between $0.2 \mathrm{~m}$ and $1.0 \mathrm{~m}$ long B) osmotic 
pressure across the FO membranes of $0.2 \mathrm{~m}$ to $1.0 \mathrm{~m}$ long $\mathrm{C}$ ) hydraulic pressure across the FO module of $0.2 \mathrm{~m}$ to $1.0 \mathrm{~m}$ long, seawater is $0.6 \mathrm{M} \mathrm{NaCl}$

The general trend in specific power consumption was an asymmetric parabola wherein a: relatively high value was apparent at short FO module length ( $0.2 \mathrm{~m} \mathrm{long}$ ); then energy consumption decreased with increasing the module length to a point of minimum electricity consumption; and increased again as the module length reached $1.0 \mathrm{~m}$. For example, for an FO process with a 1.0M draw solution the specific power consumption was $1.18 \mathrm{kWh} / \mathrm{m}^{3}$ with a $0.2 \mathrm{~m}$ module. Then this value decreased to a minimum amount of $1.15 \mathrm{kWh} / \mathrm{m}^{3}$ in a $0.4 \mathrm{~m}$ module before increasing again to a maximum amount of $1.25 \mathrm{kWh} / \mathrm{m}^{3}$ in a $1.0 \mathrm{~m}$ module. Although there was only ca. $3 \%$ decrease in the specific power consumption when the length of the FO module increased from 0.2 to $0.4 \mathrm{~m}$, such a slight decrease will make an appreciable energy saving due to the large capacity of desalination plants (typically ten's to hundreds of $\mathrm{ML}$ per day). For $1.2,1.4$, and $1.6 \mathrm{M}$ draw solution concentrations, the minimum specific power consumption was $1.26,1.35$ and $1.45 \mathrm{kWh} / \mathrm{m}^{3}$, respectively; for $0.6,0.6$ and $0.7 \mathrm{~m}$ FO modules. Short FO modules $(0.2 \mathrm{~m})$ required more energy for seawater desalination due to the insufficient dilution of the draw solution which increased the power consumption in the RO regeneration stage [Appendix A.1]. Increasing the length of the FO module to $1.0 \mathrm{~m}$ resulted in a higher dilution and subsequently reduced the power consumption in the regeneration stage. However, using a relatively long FO module increased the pumping energy in the FO module and hence the specific power consumption for seawater desalination increased accordingly.

The results indicated a sharp decrease in the osmotic pressure gradient with the length of the FO module for all draw solution concentrations due to the dilution of the draw solution by the permeate flow [Figure 5B]. The osmotic pressure across the FO membrane was almost equal for all draw solution concentrations at the end of $1 \mathrm{~m}$ FO module. Albeit, the sharpest decrease was in the case of a $1.6 \mathrm{M}$ draw solution because of the higher permeate flow rate. The net osmotic pressure at the end of the $1.0 \mathrm{~m}$ long FO module was about 1 bar. There was an additional hydraulic pressure force across the membrane (acting in the opposite direction to the osmotic pressure) which 
increased with the increase in the length of the FO module from 0.2 to $1.0 \mathrm{~m}$ [Figure 5C]. Generally, a small hydraulic pressure is required for pumping solutions in FO modules operating in DS-lumen mode. Although the pressure was larger in the FO process with $1.0 \mathrm{M}$ draw solution due to the relatively high draw solution flow rates compared to the other concentrations evaluated. As such, the RO regeneration system was responsible for the greatest power consumption for a seawater desalination process; while the FO system had an insignificant contribution to the desalination energy. However, the power consumption in the FO system was greater at low draw solution concentrations (1.0M) because of the high flow rate of the draw solution employed.

Generally, the hydraulic pressure required for pumping solutions is lower when the FO module is operating in the DS-lumen than in the FS-lumen mode. Hence the pumping energy was expected to be lower in the former operating mode. A comparison between the power consumption of FO desalination with draw solution in the lumen (DS-lumen) and with feed solution in the lumen (FS-lumen) revealed that the specific power consumption for seawater desalination in the DS-lumen mode was lower than that in the FS-lumen mode [Figure 6A]. The difference in the specific power consumption between the two operating modes increased with the length of the FO module from 0.2 to $1 \mathrm{~m}$. This situation was due to the elevated energy that was required for pumping the high flow rate feed solution in the FS-lumen mode. The largest difference in the power consumption between the two operation modes was realized in 1.0M draw solution followed by $1.2,1.4$ and $1.6 \mathrm{M}$ solutions, respectively. 

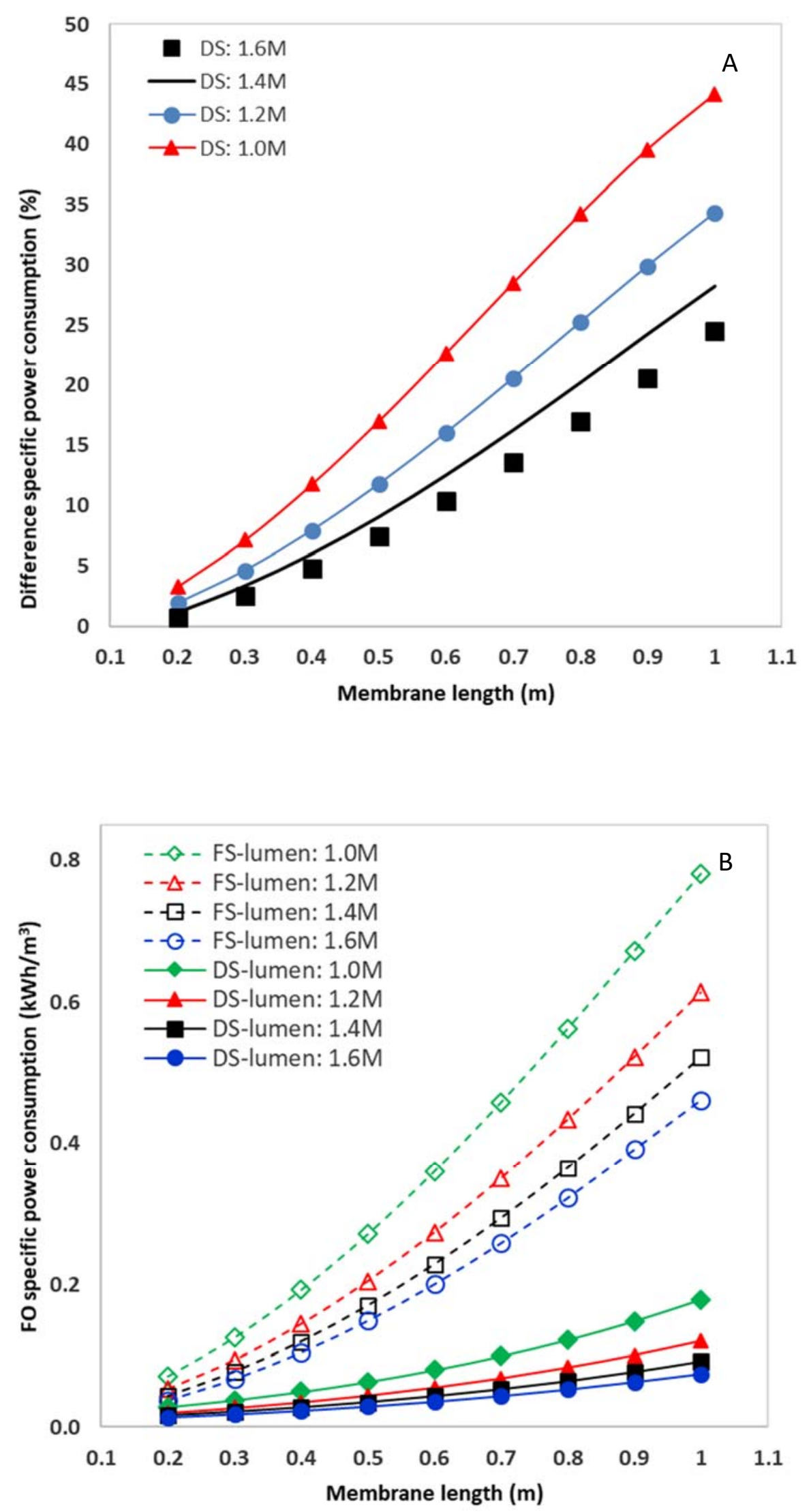


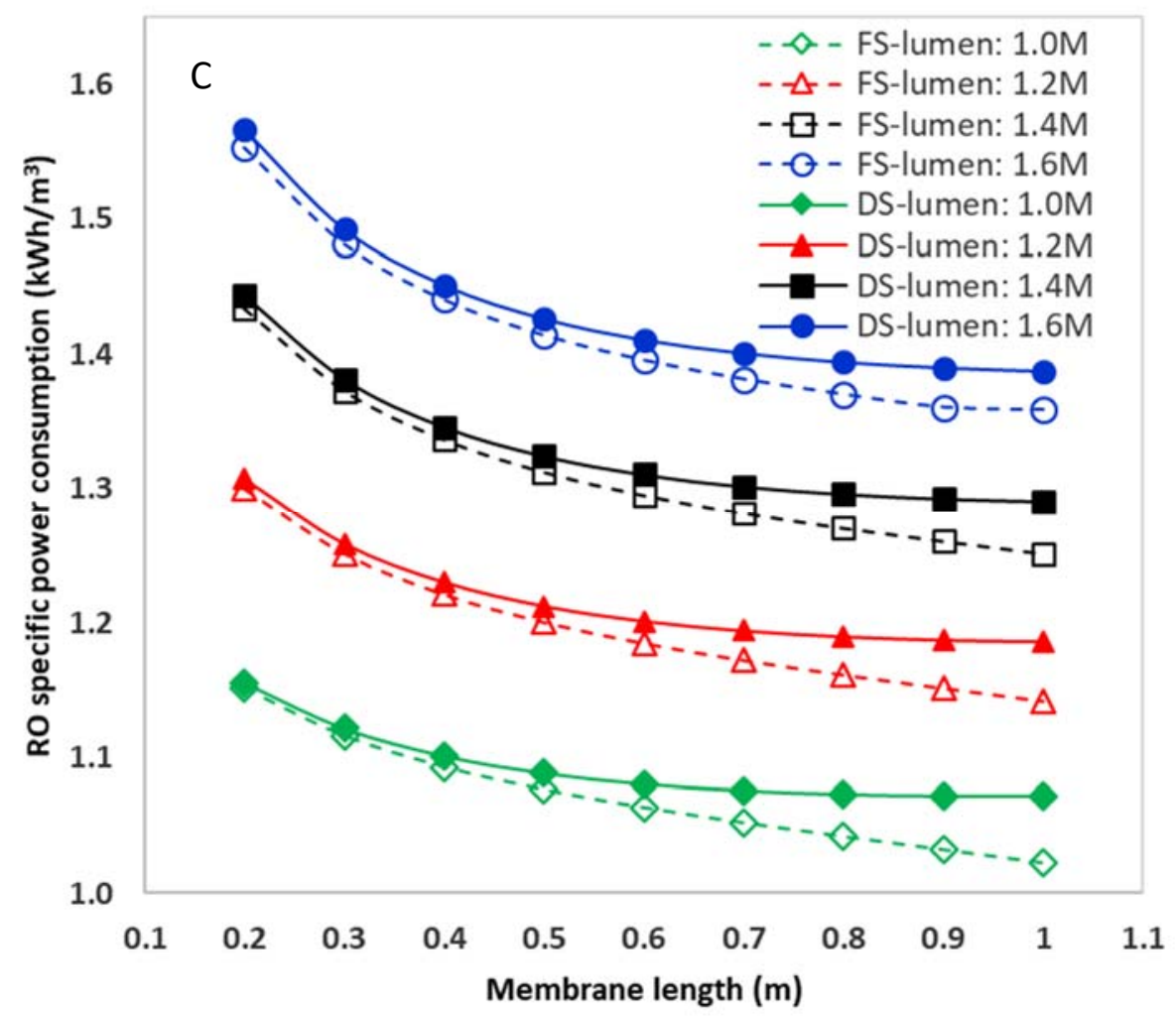

Figure 6: The specific power consumption for seawater desalination in FO modules of different length $A$ ) percentage difference in the specific power consumption between DS-lumen and FS-lumen B) specific power consumption in the FO process C) specific power consumption in the RO process, seawater is $0.6 \mathrm{M} \mathrm{NaCl}$ and draw solutions are $1.0,1.2,1.4$ and $1.6 \mathrm{M} \mathrm{NaCl}$

Figure 6B shows the specific power consumption in the FO process. The data revealed that the specific power consumption in the FO process operating in the FS-lumen mode was between 4 and 6 times more than that in the FO process operating in the DS-lumen mode. The largest difference was in $1.0 \mathrm{~m}$ long FO module with $1.0 \mathrm{M}$ draw solution followed by 1.2, 1.4 and 1.6M draw solutions, respectively. This effect was due to the larger flow rate of draw solution and lower permeate flow in the FO with lower draw solution concentration. As the length of the FO module decreased to 0.2 $\mathrm{m}$, the difference in the FO specific power consumption became smaller. However, a $0.2 \mathrm{~m}$ long FO module is not the most energy efficient for seawater desalination [Figure 5A]. On the contrary, the difference in the specific power consumption in the RO process was lower in FS-lumen than in the DS-lumen mode due to the large 
permeate flow achieved in the FS-lumen mode or when the draw solution faced the membrane active layer [Appendix A.2]. It was interesting that the specific power consumption of the RO process decreased with longer FO modules, which was in contrast to the FO process that required higher energy in longer FO modules as a result of more draw solution dilution.

In terms of the FO module, the energy-efficiency for seawater desalination varied with the length of the module and the concentration of draw solution. Depending on the concentration of draw solution, the minimum specific power consumption for seawater desalination was achieved in 0.4 to $0.7 \mathrm{~m}$ long FO modules. In light of this information, the key design criteria needed to be followed in the FO module were: (i) achieve a sufficient dilution of the draw solution during the FO treatment; and (ii) reduce the energy required for pumping the feed and draw solutions in the FO module. Apparently, the DS-lumen was more energy efficient than the FS-lumen operating mode but water flux was lower in the DS-lumen mode due to the intensive internal concentration polarization effect (membrane active layer on the shell side, FS-AL). With commercial FO membranes such as Aquaporin HF-FO which have an active layer in the lumen side, the aforementioned problem is partially solved since the FO membrane operates in the DS-AL mode when the draw solution is in the lumen (DS-lumen). However, when the membrane active layer was in the lumen side membrane fouling was a major concern in the case of low quality feed solutions where insufficient pre-treatment was in place. For the FO module to address the above design criteria, the DS-lumen mode was more energy efficient than the FS-lumen mode due to the lower energy required for pumping solutions in the FO module. Commercial FO membranes preferably have the selective layer in the lumen side to achieve both high water flux and reduce the FO pumping energy. FO membranes with the active layer in the shell side such as those supplied by Toyobo, should reduce membrane fouling when operating in DS-lumen mode. Nevertheless, this operating mode induces lower water flux due to the impact of intensive concentration polarization. Finally, the results suggested that increasing the length of the FO module was not always useful in reducing the desalination energy. Therefore, this parameter should be optimized based upon consideration of the concentration of draw solution 
used in the FO process.

\subsection{Practical Applications}

The length of the FO module and the concentration of draw solution could be varied in the FO process with a common objective of reducing the desalination energy. The results showed that the FO desalination process is more energy efficient when the solution of lower flow rate is in the lumen; i.e. DS-lumen mode; due to lower pumping energy. Increasing the concentration of draw solution induced more permeate flow rate but unfortunately increased the energy requirements in the RO stage. Selection of a proper module length makes the process even more complicated since longer modules facilitated the dilution of the draw solution but concomitantly increased the pumping energy. A simple cost analysis was conducted to identify the optimum module length and the concentration of draw solution for seawater desalination by an FO module between 0.2 and $1.0 \mathrm{~m}$ long. It was assumed that the: FO membrane cost was in the range 15 to 19 USD/m²; energy cost was 25 cent/kWh (usually between 25 and 40 cent/kWh); and the membrane lifetime was 5 years [9].

Table 2 shows the predicted cost of seawater desalination by the FO system at a flow rate of $240 \mathrm{~m}^{3} / \mathrm{h}$. Calculations revealed that the number of FO modules required for seawater desalination decreased as the length of the FO module increased from 0.2 to $1.0 \mathrm{~m}$. The number of FO modules also decreased as the concentration of the draw solution increased due to the higher permeate flow rate in the longer FO modules using 1.6M draw solution [Appendix A.2]. Furthermore, the lower number of the FO modules required in FO operating in FS-lumen mode was attributed to: (i) higher permeate flow rate when the draw solution faced the membrane active layer in the FS-lumen mode; and (ii) the larger hydraulic pressure gradient across the FO membrane (i.e. PAFO process) [Figure 4A]. Despite the lower number of the FO modules required in the FS-lumen mode, more energy was required for operation compared to the DS-lumen mode [Figure 6A]. Therefore, the cost of seawater desalination (membrane and energy cost) was evaluated and results suggested this cost was lower in the DS-lumen mode rather than in FS-lumen mode [Figure 7]. 
Table 2: Number of FO modules required for $240 \mathrm{~m}^{3} / \mathrm{h}$ seawater desalination plant, FO module is $20 \mathrm{~m}^{2}$ active area, seawater TDS $0.6 \mathrm{M} \mathrm{NaCl}$, draw solution $\mathrm{NaCl}$, cost of hollow fibre FO is $18 \mathrm{USD} / \mathrm{m}^{2}$ and cost of energy is $0.25 \mathrm{USD} / \mathrm{kW}$

\begin{tabular}{|c|c|c|c|c|c|c|c|c|}
\hline \multirow{2}{*}{$\begin{array}{c}\text { Module } \\
\text { length }\end{array}$} & \multicolumn{6}{|c|}{ FO membrane module } \\
\cline { 2 - 9 } & \multicolumn{6}{|c|}{ DS-lumen } & \multicolumn{4}{c|}{ FS-Iumen } \\
\cline { 2 - 9 } & $1.0 \mathrm{M}$ & $1.2 \mathrm{M}$ & $1.4 \mathrm{M}$ & $1.6 \mathrm{M}$ & $1.0 \mathrm{M}$ & $1.2 \mathrm{M}$ & $1.4 \mathrm{M}$ & $1.6 \mathrm{M}$ \\
\hline 0.2 & 8300 & 6156 & 5078 & 4424 & 8045 & 5954 & 4895 & 4253 \\
\hline 0.3 & 6571 & 4884 & 4035 & 3525 & 6337 & 4724 & 3906 & 3411 \\
\hline 0.4 & 5763 & 4279 & 3536 & 3092 & 5478 & 4107 & 3410 & 2987 \\
\hline 0.5 & 5325 & 3943 & 3258 & 2846 & 4946 & 3730 & 3108 & 2730 \\
\hline 0.6 & 5071 & 3744 & 3087 & 2695 & 4569 & 3469 & 2900 & 2553 \\
\hline 0.7 & 4923 & 3622 & 2981 & 2600 & 4271 & 3267 & 2742 & 2419 \\
\hline 0.8 & 4844 & 3549 & 2914 & 2538 & 4018 & 3099 & 2611 & 2310 \\
\hline 0.9 & 4810 & 3507 & 2873 & 2498 & 3791 & 2950 & 2499 & 2217 \\
\hline 1 & 4810 & 3489 & 2850 & 2474 & 3572 & 2808 & 2391 & 2118 \\
\hline
\end{tabular}

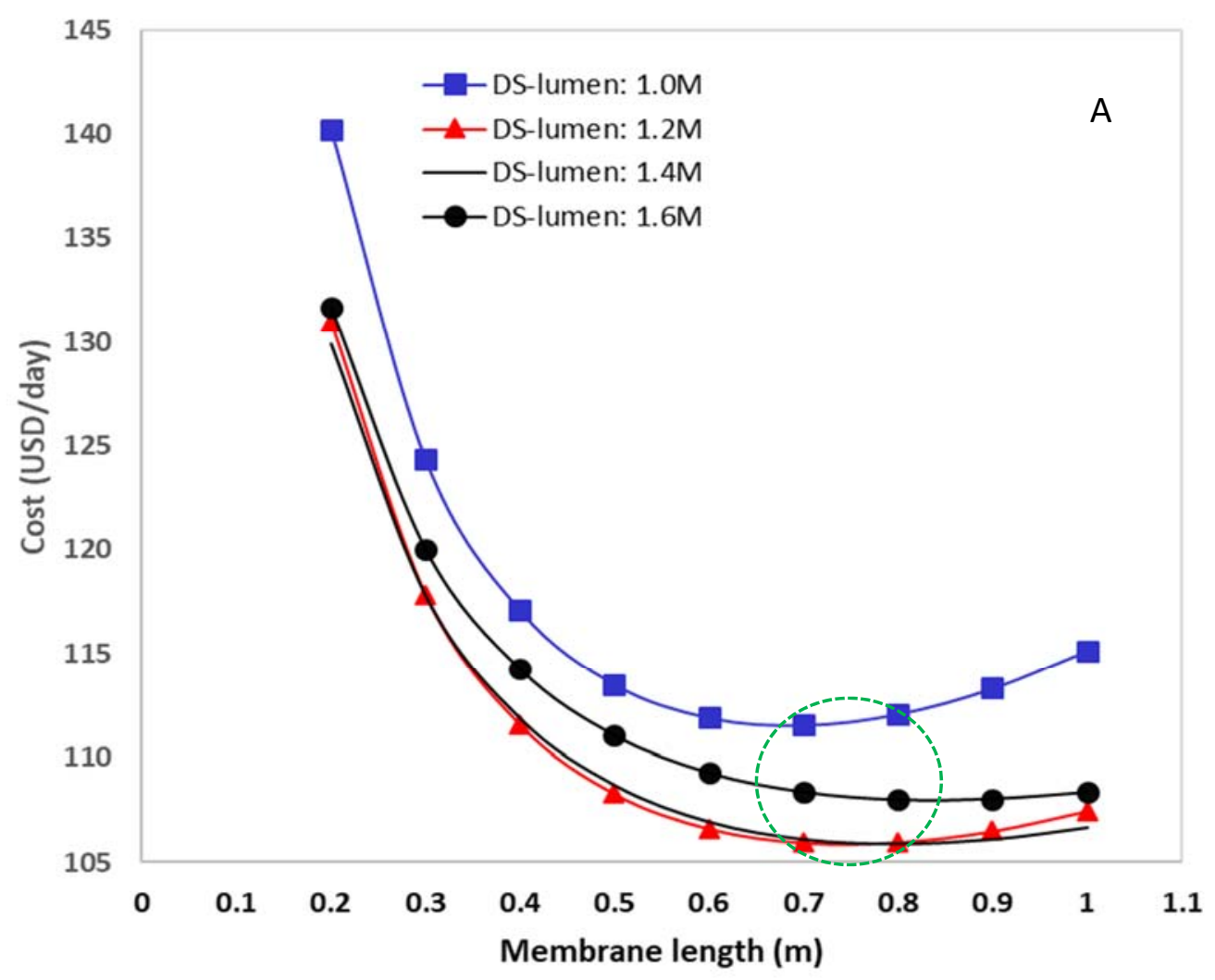




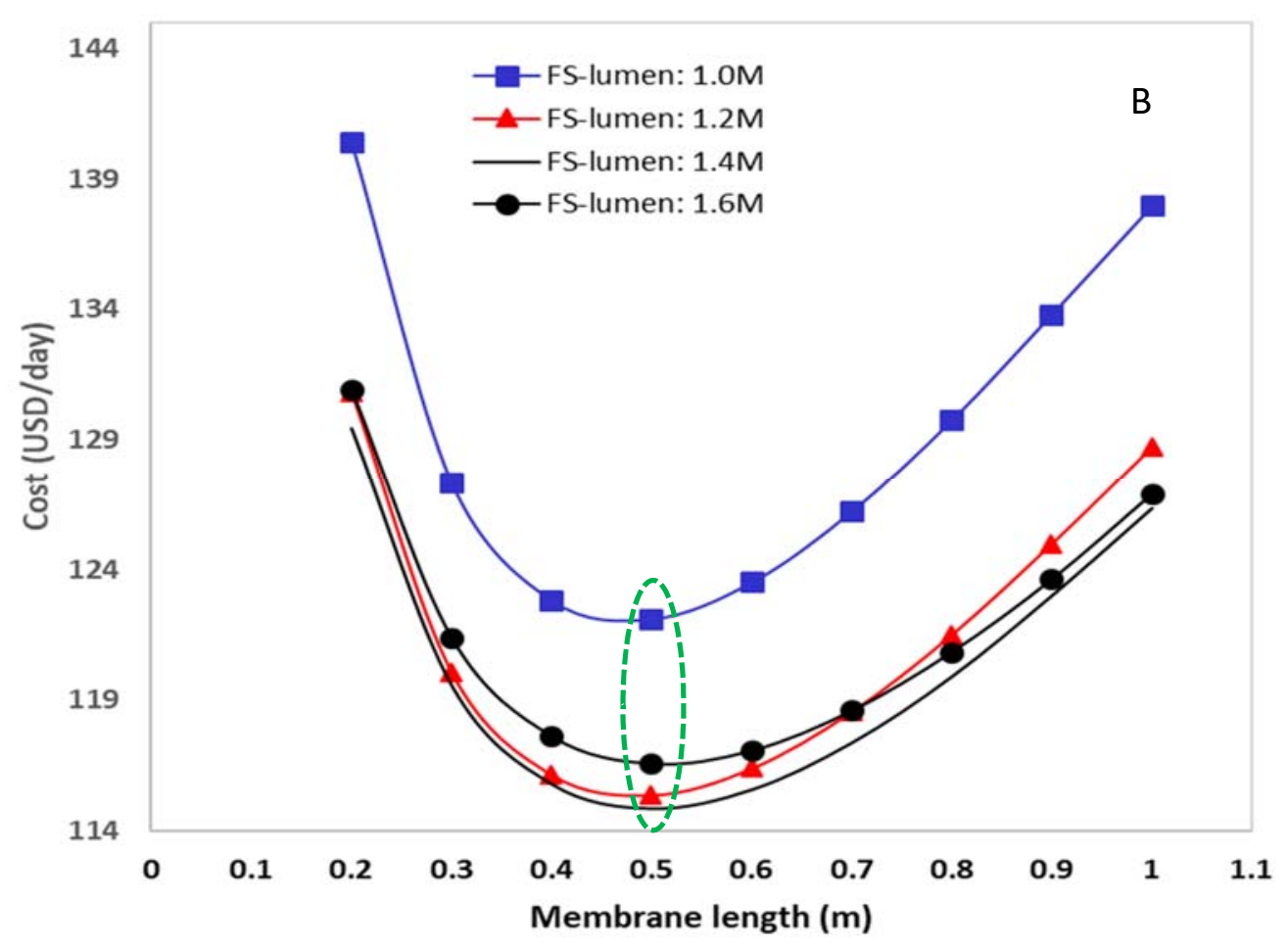

Figure 7: Cost of FO membrane operation in USD/day for A) FO operating in the DSlumen mode B) FO operating in the FS-lumen mode.

For an FO system operating in DS-lumen mode, 1.2 and 1.4M draw solutions exhibited the lowest cost for seawater desalination followed by 1.6 and 1.0 draw solutions, respectively [Figure 7A]. An FO process with $1.0 \mathrm{M}$ draw solution was the least costeffective amongst the draw solutions due to the large membrane area required for seawater desalination. A 1.0M draw solution required 8300 FO modules, which was twice the number of FO modules required when using a 1.6M draw solution (4424 FO modules) [Table 2]. Interestingly, FO modules 0.7 to $0.8 \mathrm{~m}$ long exhibited the most cost-effective seawater desalination process in the case of 1.2 and $1.4 \mathrm{M}$ draw solutions. For a $240 \mathrm{~m}^{3} / \mathrm{h}$ seawater desalination plant the cost of desalination was approximately 106 USD/h for a 1.2 and $1.4 \mathrm{M}$ draw solution FO process; whereas it was 108 and 112 USD/h for 1.6 and 1.0M draw solution FO processes, respectively. Based on these results, the cost of a FO desalination process operating in the DS-lumen mode became more economic with 1.2 to $1.4 \mathrm{M}$ draw solution and a $0.7 \mathrm{~m}$ long FO module. Increasing the length of the FO module or the concentration of draw solution increased the cost of FO desalination. Reducing the concentration of draw solution to 
1.0M caused a sharp increase in the cost of FO desalination and doubled the number of FO modules required in the FO system.

For the FO process operating in the FS-lumen mode, results indicated that 1.2 and 1.4M draw solutions were more cost effective than 1.0 and $1.6 \mathrm{M}$ draw solutions [Figure 7B]. For a $240 \mathrm{~m}^{3} / \mathrm{h}$ desalination plant, the lowest desalination cost of 115 USD/h was obtained in a $0.5 \mathrm{~m}$ FO module using 1.2 and $1.4 \mathrm{M}$ draw solution. The corresponding costs for a $0.5 \mathrm{M}$ FO module using 1.0 and $1.6 \mathrm{M}$ draw solutions were 122 and 117 USD/h, respectively. It was apparent that the FO process operating in the FS-lumen mode was 8 to $9.5 \%$, more expensive than the FO process operating in the DS-lumen mode. For the FO unit operating in the FS-lumen mode a 1.2 to $1.4 \mathrm{M}$ draw solution concentration combined with a $0.5 \mathrm{~m}$ long FO module was more efficient and economical for seawater desalination. In a practical framework, the performance of the FO membrane and energy cost vary over time and from one place to another, which will affect the efficiency of the FO process. Therefore, these parameters should be updated upon the consideration of desalination by the FO process.

Commercial hollow follow fibre FO membranes available with active layer in the lumen side (e.g. Aquaporin A/S), or active layer in the shell side (Toyobo Membranes) are not recommended because of the predicted high-energy requirements. However, for a FO membrane with an active layer in the lumen side treating a low quality feed solution such as wastewater effluent, the FS-lumen mode would be a potential option to reduce membrane fouling [28]. The recommended length of the FO module and the concentration of the draw solution should be $0.5 \mathrm{~m}$ and $1.2 \mathrm{M}$, respectively; in order to make the FO process more cost-effective when operating in the FS-lumen mode. Switching the FO operating mode to DS-lumen and the active layer in the shell side reduced the pumping energy in the FO module [Figure 6A]. In such a case, the length of the FO module should be about $0.7 \mathrm{~m}$ and the concentration of draw solution 1.2M. Therefore, membrane manufacturers should custom design the FO module based on the application and the quality of solutions. Shell side-active layer membrane was more effective in reducing both fouling and the energy requirements for pumping solutions in the FO module provided it operated in the DS-lumen mode. Membranes 
with lumen side-active layer, such as Aquaporin HF-FO, exhibit higher water flux when operated in the DS-lumen side. Such a membrane may suffer fouling when the quality of feed water is low and switching the operating mode to FS-lumen should increase the energy requirements of the FO process. Otherwise, draw solution is recommended to be in the lumen side to reduce the pumping energy with an exemption in the case of active layer in the lumen side and when the quality of feed solution is low.

\section{Conclusions}

The study presented a method for the design of FO membrane module, underlining the significance optimizing the length of the FO module to reduce the power consumption of seawater desalination. The results showed that the FO desalination process is more energy efficient when low flow rate draw solution is in the lumen side while the high flow rate feed solution is in the shell side. Increasing the concentration of draw solution induces larger permeate flow rate but also increases the power consumption of seawater desalination. The results demonstrated that low concentration draw solution, $1.0 \mathrm{M}$, and high concentration draw solution, $1.6 \mathrm{M}$, were less energy efficient than $1.2 \mathrm{M}$ and $1.4 \mathrm{M}$ draw solutions. The length of the FO module should be carefully optimized to reduce the desalination energy. Although long FO membrane exhibits larger permeate flow than short module, but the energy of pumping solutions increases the power consumption of desalination. The optimum length of the FO membrane operating in DS-lumen mode was found to be $0.7 \mathrm{~m}$. The results of this study will be useful tool in the design and manufacturing FO membrane modules.

\section{Acknowledgement:}

Authors would like to acknowledge the support form Qatar Foundation NPRP10 research fund to perform this study.

\section{Appendix}

\section{A.1 Impact of increasing the flow rate of draw solution}

Increasing the flow rate of the draw solution increases the osmotic pressure of the 
draw solution going to the RO regeneration stage; and hence the energy requirements for seawater desalination. This situation holds true for both operating modes, i.e. DSlumen and FS-lumen. For the FS-lumen mode, the osmotic pressure of draw solution going to the RO regeneration stage increased from 35 to 51 bar due to the increase in the flow rate from 95 to $395 \mathrm{~L} / \mathrm{h}$, respectively. The corresponding values for FS-lumen mode were 38 and 54 bar for draw solution flow rates of 95 and $395 \mathrm{~L} / \mathrm{h}$, respectively. As the osmotic pressure of the draw solution increased, the energy required for separating solute from fresh water increased accordingly. Furthermore, increasing the flow rate of draw solution increased the pumping energy into the FO module.

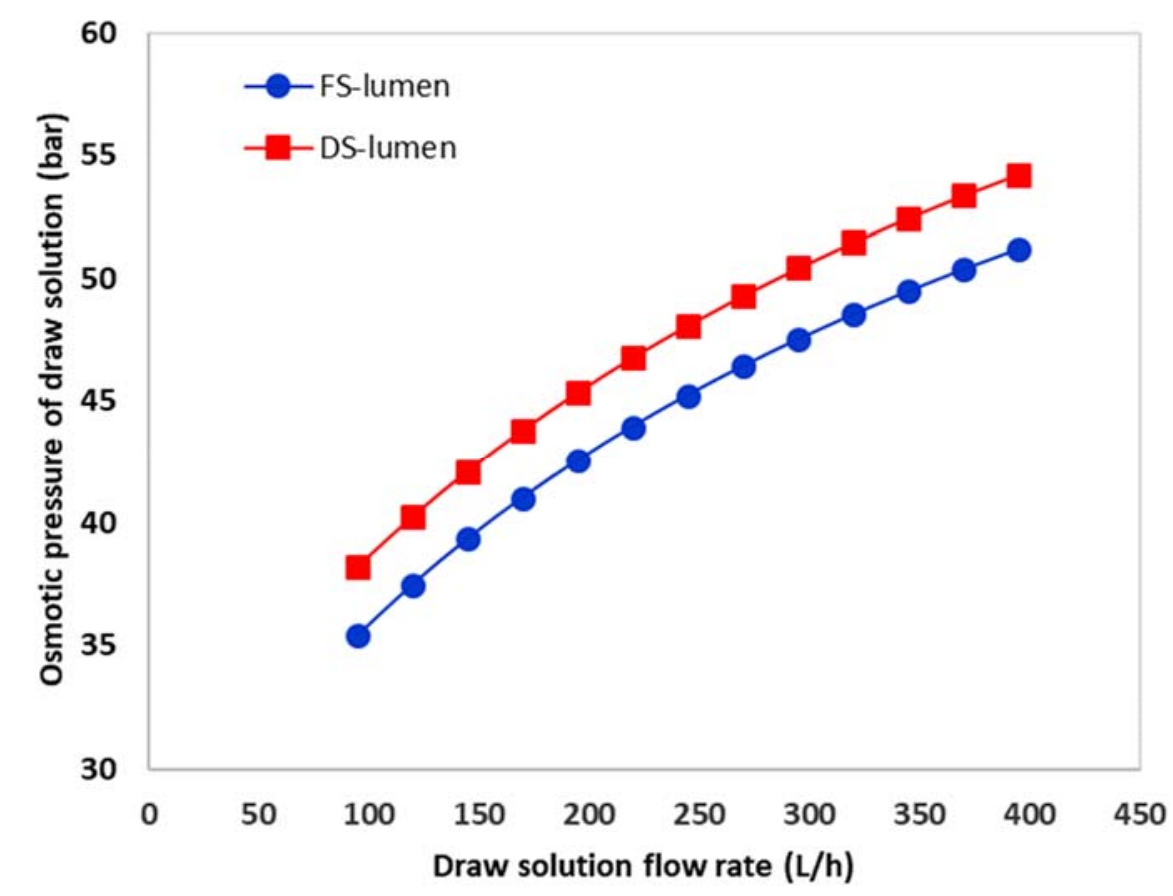

Figure A.1: Impact of draw solution flow rate on the osmotic pressure of draw solution going to the RO regeneration process: membrane area was $20 \mathrm{~m}^{2}$; feed flow rate was $400 \mathrm{~L} / \mathrm{h}$; FO membrane was $1.0 \mathrm{~m}$ long; draw solution concentration was

1.6 M NaCl; and feed solution concentration was $0.6 \mathrm{M} \mathrm{NaCl}$

\section{A.2. Impact of flow direction on the permeate flow}

Permeate flow in the FO process increased as the length of the FO module increased from 0.2 to $1.0 \mathrm{~m}$ for all draw solutions. Permeate flow rate was also higher in the FO process with a $1.6 \mathrm{M}$ draw solution because of the larger osmotic pressure driving 
force across the membrane. For FO process operation in the DS-lumen mode, the largest permeate flow was $97 \mathrm{~L} / \mathrm{h}$ and achieved in a $1.0 \mathrm{~m}$ long nodule with a $1.6 \mathrm{M}$ draw solution. The permeate flow rate decreased as the concentration of draw solution decreased from 1.6 to 1.0 M. An FO process operating in the FS-lumen mode exhibited higher permeate flow rate than that operating in the DS-lumen mode with $113 \mathrm{~L} / \mathrm{h}$ permeate flow rate in a $1.0 \mathrm{~m}$ long FO module and with a $1.6 \mathrm{M}$ draw solution. Permeate flow rate was larger in the FS-lumen mode because of the: (i) larger water flux when the draw solution faced the membrane active layer; and (ii) the higher osmotic pressure gradient across the membrane in the FS-lumen mode.
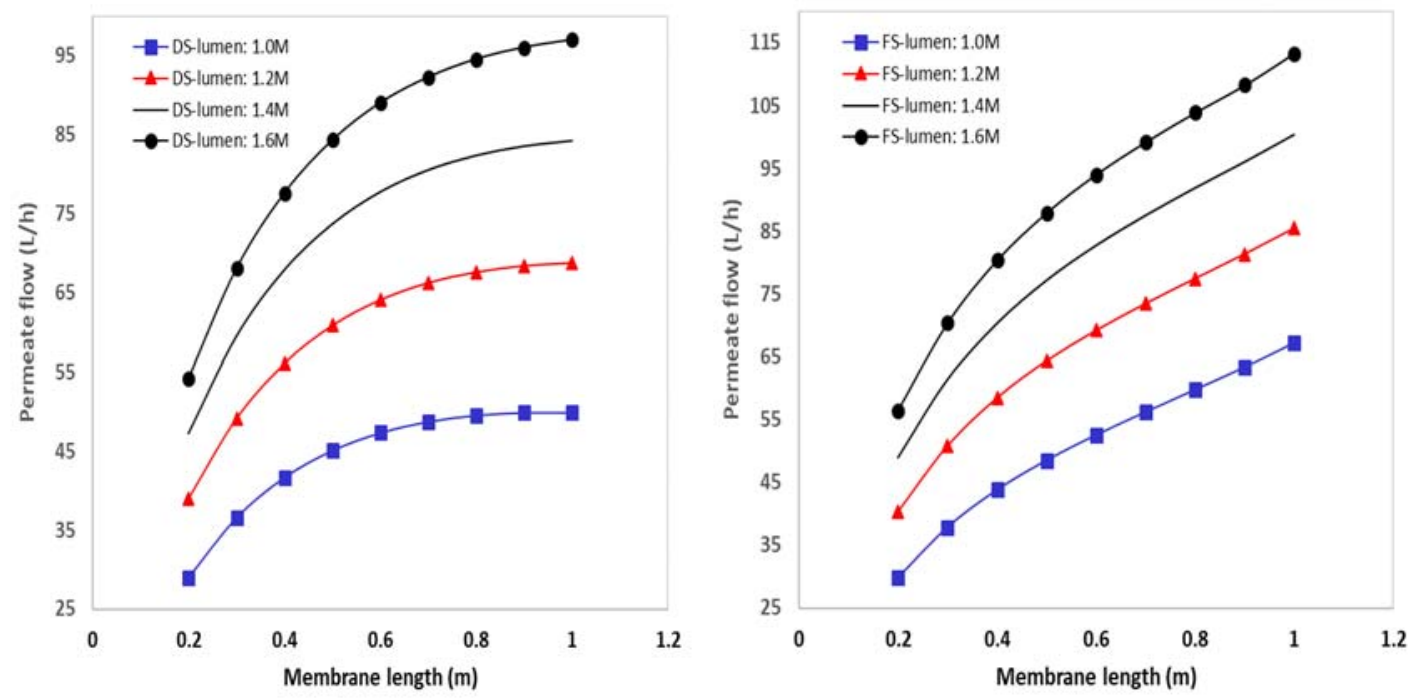

Figure A.2: Permeate flow in FO modules of 0.2 to $1.0 \mathrm{~m}$ long: (A) DS-lumen side; (B) FS-lumen side. Feed flow rate was $400 \mathrm{~L} / \mathrm{h}$, seawater concentration $0.6 \mathrm{M} \mathrm{NaCl}$, and the FO membrane area was $20 \mathrm{~m}^{2}$

\section{$\underline{\text { 6. References }}$}

[1] N. Akther, A. Sodiq, A. Giwa, S. Daer, H.A. Arafat, S.W. Hasan, Recent advancements in forward osmosis desalination: A review, Chemical Engineering Journal, 281 (2015) 502-522.

[2] A. Altaee, Theoretical study on feed water designs to reverse osmosis pressure vessel, Desalination, 326 (2013) 1-9.

[3] N. Fujiwara, H. Matsuyama, High recovery system in seawater reverse osmosis 
plants, J. Appl. Polym. Sci., 108 (2008) 3403-3410.

[4] A. Shahmansouri, C. Bellona, Nanofiltration technology in water treatment and reuse: Applications and costs, Water Science and Technology, 71 (2015) 309-319.

[5] A. Altaee, G. Zaragoza, H.R. van Tonningen, Comparison between Forward Osmosis-Reverse Osmosis and Reverse Osmosis processes for seawater desalination, Desalination, 336 (2014) 50-57.

[6] D. Attarde, M. Jain, P.K. Singh, S.K. Gupta, Energy-efficient seawater desalination and wastewater treatment using osmotically driven membrane processes, Desalination, 413 (2017) 86-100.

[7] R. Valladares Linares, Z. Li, S. Sarp, S. Bucs, G. Amy, J.S. Vrouwenvelder, Forward osmosis niches in seawater desalination and wastewater reuse, Water Research, 66 (2014) 122-139.

[8] B. Corzo, T. de la Torre, C. Sans, E. Ferrero, J.J. Malfeito, Evaluation of draw solutions and commercially available forward osmosis membrane modules for wastewater reclamation at pilot scale, Chemical Engineering Journal, 326 (2017) 1-8.

[9] A. Altaee, G.J. Millar, G. Zaragoza, A. Sharif, Energy efficiency of RO and FO-RO system for high-salinity seawater treatment, Clean Technologies and Environmental Policy, 19 (2017) 77-91.

[10] Y. Chun, S.J. Kim, G.J. Millar, D. Mulcahy, I.S. Kim, L. Zou, Forward osmosis as a pre-treatment for treating coal seam gas associated water: Flux and fouling behaviour, Desalination, 403 (2017) 144-152.

[11] J. Ren, J.R. McCutcheon, A new commercial biomimetic hollow fiber membrane for forward osmosis, Desalination, 442 (2018) 44-50.

[12] D. Attarde, M. Jain, K. Chaudhary, S.K. Gupta, Osmotically driven membrane processes by using a spiral wound module - Modeling, experimentation and numerical parameter estimation, Desalination, 361 (2015) 81-94.

[13] S. Lin, A.P. Straub, M. Elimelech, Thermodynamic limits of extractable energy by pressure retarded osmosis, Energy and Environmental Science, 7 (2014) 2706-2714.

[14] A.H. Hawari, N. Kamal, A. Altaee, Combined influence of temperature and flow rate of feeds on the performance of forward osmosis, Desalination, 398 (2016) 98105.

[15] N.R.J.D. Mermier, C.P. Borges, Direct osmosis process for power generation using 
salinity gradient: FO/PRO pilot plant investigation using hollow fiber modules, Chemical Engineering and Processing: Process Intensification, 103 (2016) 27-36.

[16] Masafumi Shibuya, Masahiro Yasukawa, Shohei Goda, Hidehiko Sakurai, Tomoki Takahashi, Mitsuru Higa, Hideto Matsuyama, Experimental and theoretical study of a forward osmosis hollow fiber Membrane module with a cross-wound configuration, Desalination, V 504 (2016), 10-19.

[17] Dinesh Attarde, Manish Jain, Preet Kamal Singh, Sharad Kumar Gupta, Energyefficient seawater desalination and wastewater treatment using osmotically driven membrane processes, Desalination, V 413 (2017), 86-100.

[18] Chun Feng Wan, Tai-Shung Chung, Techno-economic evaluation of various RO+PRO and RO+FO integrated processes, Applied Energy, V 212 (2018), 1038-1050 [19] Yasuhiko Tanaka, Masahiro Yasukawa, Shohei Goda, Hidehiko Sakurai, Masafumi Shibuya, Tomoki Takahashi, Michimasa Kishimoto, Mitsuru Higa, Hideto Matsuyama, Experimental and simulation studies of two types of 5-inch scale hollow fiber membrane modules for pressure-retarded osmosis, Desalination, V 447 (2018), 133146

[20] B.S. Chanukya, S. Patil, N.K. Rastogi, Influence of concentration polarization on flux behavior in forward osmosis during desalination using ammonium bicarbonate, Desalination, 312 (2013) 39-44.

[21] M. Sekino, Precise analytical model of hollow fiber reverse osmosis modules, Journal of Membrane Science, 85 (1993) 241-252.

[22] N.M. Mazlan, D. Peshev, A.G. Livingston, Energy consumption for desalination - A comparison of forward osmosis with reverse osmosis, and the potential for perfect membranes, Desalination, 377 (2016) 138-151.

[23] A. Altaee, J. Zhou, A. Alhathal Alanezi, G. Zaragoza, Pressure retarded osmosis process for power generation: Feasibility, energy balance and controlling parameters, Applied Energy, 206 (2017) 303-311.

[24] A. Zhu, P.D. Christofides, Y. Cohen, Minimization of energy consumption for a two-pass membrane desalination: Effect of energy recovery, membrane rejection and retentate recycling, Journal of Membrane Science, 339 (2009) 126-137.

[25] N.N. Bui, J.T. Arena, J.R. McCutcheon, Proper accounting of mass transfer resistances in forward osmosis: Improving the accuracy of model predictions of 
structural parameter, Journal of Membrane Science, 492 (2015) 289-302.

[26] E. Nagy, A general, resistance-in-series, salt- and water flux models for forward osmosis and pressure-retarded osmosis for energy generation, Journal of Membrane Science, 460 (2014) 71-81.

[27] A. Altaee, G. Zaragoza, A. Sharif, Pressure retarded osmosis for power generation and seawater desalination: Performance analysis, Desalination, 344 (2014) 108-115. [28] C.Y. Tang, Q. She, W.C.L. Lay, R. Wang, A.G. Fane, Coupled effects of internal concentration polarization and fouling on flux behavior of forward osmosis membranes during humic acid filtration, Journal of Membrane Science, 354 (2010) 123-133.

[29] Q. She, Y.K.W. Wong, S. Zhao, C.Y. Tang, Organic fouling in pressure retarded osmosis: Experiments, mechanisms and implications, Journal of Membrane Science, 428 (2013) 181-189.

[30] C.H. Tan, H.Y. Ng, Revised external and internal concentration polarization models to improve flux prediction in forward osmosis process, Desalination, 309 (2013) 125140. 